Loma Linda University

TheScholarsRepository@LLU: Digital Archive of Research, Scholarship \& Creative Works

Loma Linda University Electronic Theses, Dissertations \& Projects

$12-2004$

\title{
The Effect of Rapid Maxillary Expansion on Nasal Cavity Volume and Nasal Airway Resistance
}

Todd Ehrler

Follow this and additional works at: https://scholarsrepository.llu.edu/etd

Part of the Other Dentistry Commons

\section{Recommended Citation}

Ehrler, Todd, "The Effect of Rapid Maxillary Expansion on Nasal Cavity Volume and Nasal Airway Resistance" (2004). Loma Linda University Electronic Theses, Dissertations \& Projects. 1248.

https://scholarsrepository.llu.edu/etd/1248

This Thesis is brought to you for free and open access by TheScholarsRepository@LLU: Digital Archive of Research, Scholarship \& Creative Works. It has been accepted for inclusion in Loma Linda University Electronic Theses, Dissertations \& Projects by an authorized administrator of TheScholarsRepository@LLU: Digital Archive of Research, Scholarship \& Creative Works. For more information, please contact scholarsrepository@llu.edu. 


\title{
UNIVERSITY LIBRARY \\ LOMA LINDA, CALIFORNIA
}

\author{
LOMA LINDA UNIVERSITY \\ Graduate School
}

The Effect of Rapid Maxillary Expansion on Nasal Cavity Volume and Nasal Airway Resistance

by

Todd Ehrler

\begin{abstract}
A Thesis submitted in partial satisfaction of the requirements for the degree of Master of Science
\end{abstract}

December 2004 
Each person whose signature appears below certifies that this dissertation in his opinion is adequate, in scope and quality, as a thesis for the degree Master of Science.

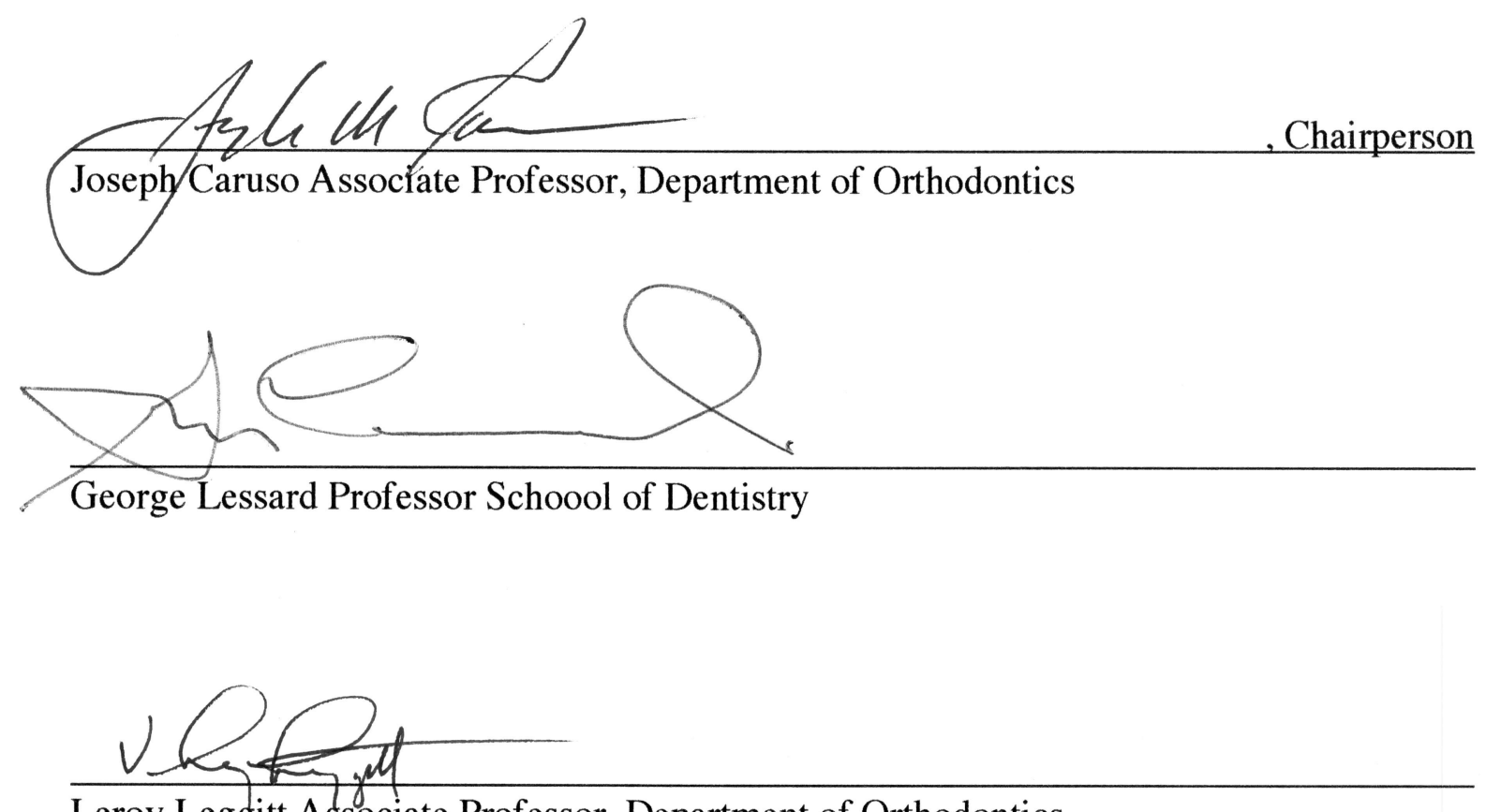

Leroy Leggitt Associate Professor, Department of Orthodontics 


\section{ACKNOWLEDGEMENTS}

I wish to sincerely thank all of my committee members for there substantial efforts in the research process. Their experience and guidance made this study possible. Dana Koops for organizing and searching endlessly for patient data. Jon Robinson for his tremendous work in developing the method of volumetric measurements. My wife, for standing by my side through it all, never questioning and always understanding. 


\section{TABLE OF CONTENTS}

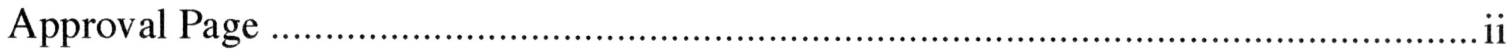

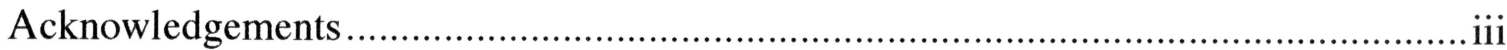

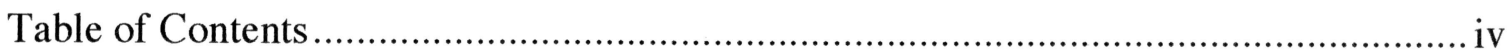

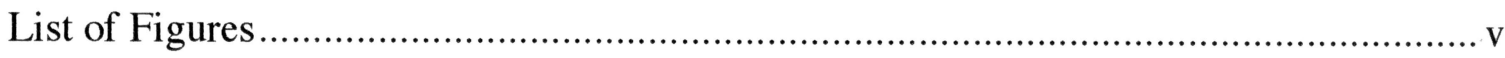

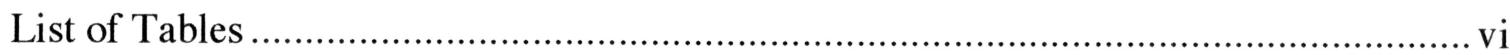

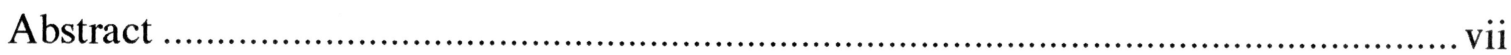

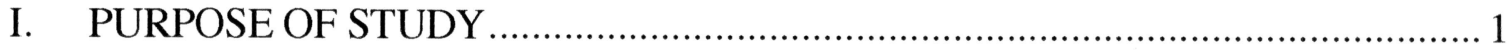

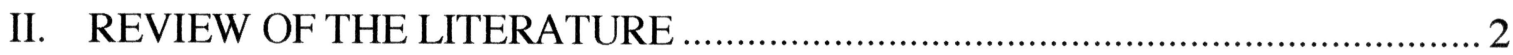

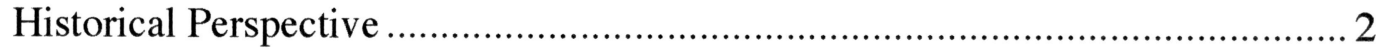

Limitations of Two Dimensional Analysis ....................................................... 4

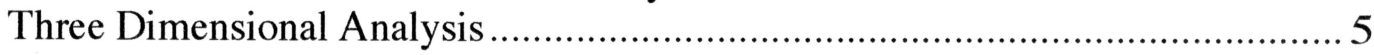

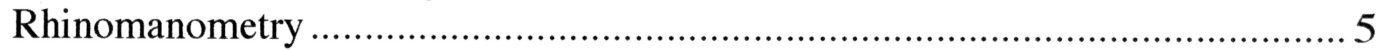

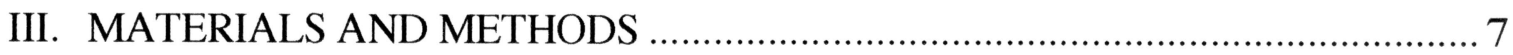

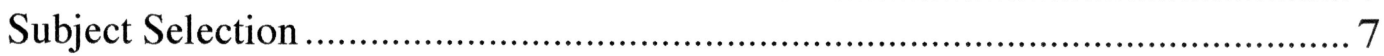

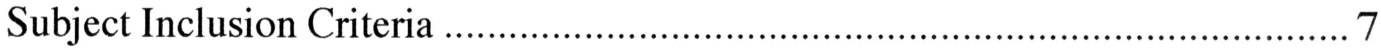

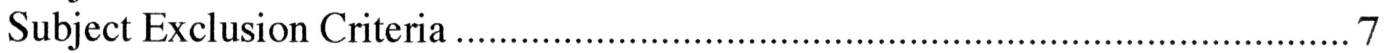

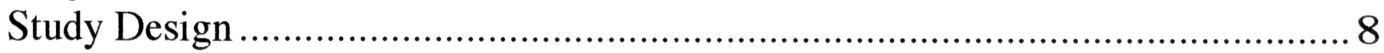

Method of Determining Volumetric Change of Nasal Cavity .............................. 9

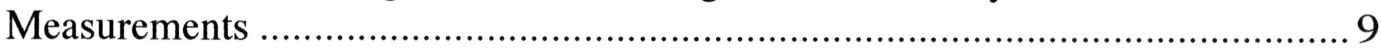

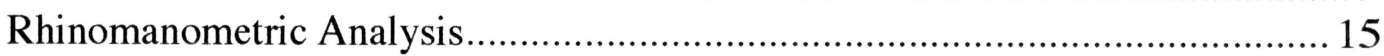

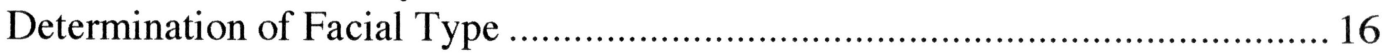

IV. RESULTS

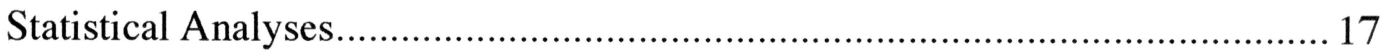

Descriptive Statistics of Continuous Variables................................................. 17

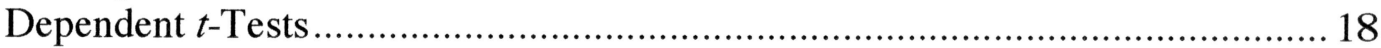

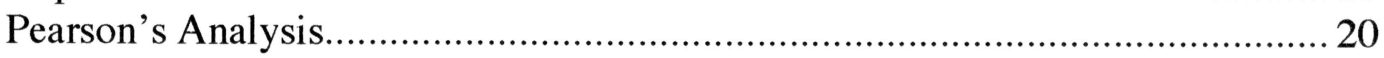

Face type: ANOVA and Post Hoc Analyses.................................................... 24

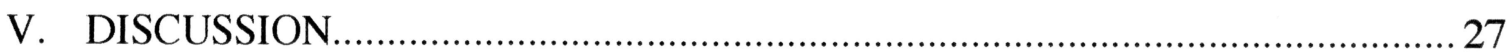

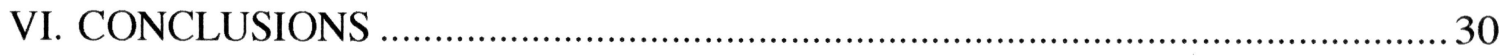

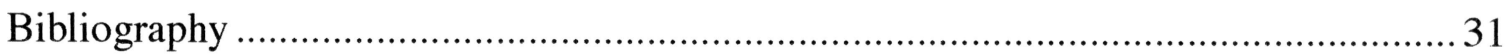

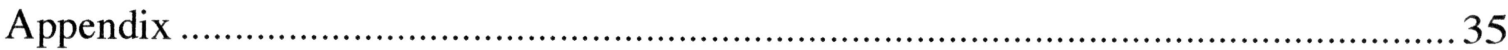




\section{LIST OF FIGURES}

Figure

1. Vertical alignment of cusp tips 9

2. Measurement of linear expansion.......................................................

3. Inferior and superior boundary of nasal cavity .................................... 11

4. Anterior and posterior boundary of nasal cavity .................................... 12

5. Sequential series of tomographic slices................................................... 13

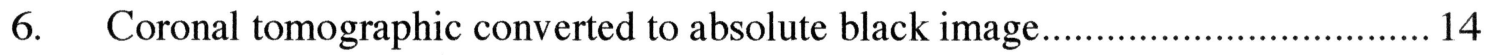

7. Three dimensional rendering of nasal cavity volume................................... 14

8. Three dimensional rendering of nasal cavity volume................................... 14

9. Three dimensional rendering of nasal cavity volume................................. 15

10. Three dimensional rendering of nasal cavity volume................................. 15

11. Three dimensional rendering of nasal cavity volume............................... 15

12. Three dimensional rendering of nasal cavity volume.................................. 15

13. Box whisker: Volume before and after RME. ........................................ 19

14. Box whisker: Nasal airway resistance (NAR) before and after RME................ 19

15. Scatterplot: Before RME NAR vs. Change in NAR ...................................... 22

16. Scatterplot: Volume Pre RME vs. \% Change in Volume ................................. 22

17. Scatterplot: Pre Expansion NAR vs. \% Change in NAR ................................. 23

18. Scatterplot: Change in NAR vs. Change in Volume ..................................... 23

19. Scatterplot: Change in volume vs. linear expansion $(\mathrm{mm})$............................ 24

20. Box Whisker: \% Change in Nasal Airway Resistance vs. Face Type............... 26 


\section{LIST OF TABLES}

Table Page

1. Descriptive statistics for continuous variables ............................................... 18

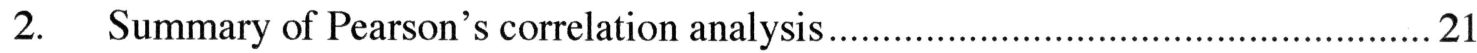

3. ANOVA. Continuous Variables by Face Type ................................................... 25

4. Post-Hoc analysis: Significant difference in \% change of NAR between

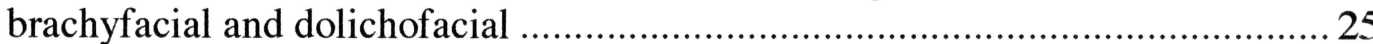




\section{ABSTRACT OF THE THESIS \\ The Effect of Rapid Maxillary Expansion on Nasal Cavity Volume and Nasal Airway Resistance}

by

\section{Todd Ehrler}

Master of Science, Graduate Program in Orthodontics and Dentofacial Orthopaedics Loma Linda University, December 2004

Dr. Joseph Caruso, Chairperson

This study examined the effects of Rapid Maxillary Expansion (RME). Using Cone Beam CT scanning technology and Rhinomanometry, the volume and nasal airway resistance (NAR) of the nasal cavity was measured immediately before and after RME.

27 subjects (16 female, and 11 male), ages 9-18 were enrolled in the study. After RME all subjects had a statistically significant increase in nasal cavity volume. The pre expansion group experienced a statistically significant reduction in NAR when compared to the post expansion group. Individuals with a high pre expansion NAR experienced the greatest reduction in NAR. The correlation between change in volume and change in NAR proved to be weak. A comparison was made among facial types; Dolichofacial individuals experienced a greater reduction in NAR to the other face types, especially when compared to Brachyfacial individuals. 


\section{PURPOSE OF STUDY}

The purpose of this study was to measure the effects of RME on the nasal cavity volume and nasal airway resistance. A comparison among facial types and nasal cavity volume and nasal airway resistance was investigated as well. 


\section{REVIEW OF THE LITERATURE}

\section{Historical Perspective}

The subject of oral respiration and its effect on craniofacial development has been prevalent in the orthodontic and medical literature for more than a century. Investigators have struggled to prove or deny the relationship between nasorespiratory function and craniofacial development. Rapid maxillary expansion (RME) was initially used as a technique to resolve dental crowding or to correct transverse discrepancies between the maxillary and mandibular arches. However, during the expansion process many patients reported an increased ability to breathe through the nose. As a result of this, some clinicians use RME as a treatment modality for oral respiration and its relationship to abnormal craniofacial development.

Moss' "functional matrix theory" developed in the 1960's, was at the forefront of the debate. His "form is determined by function" philosophies help to elucidate the craniofacial etiology characteristic of mouth breathers. ${ }^{1}$

Numerous studies have found a correlation between oral-respiration and a host of occlusal and craniofacial abnormalities. Constricted "V" shaped maxilla, high palatal arch, elongation of the lower face height, open bite, cross bite, and a" clockwise" rotation of the mandible to a more vertical and posterior position..$^{2-5}$ Interestingly, patients who returned to nasal breathing after airway correcting procedures, such as adenoid removal, showed changes in growth back towards normal. ${ }^{6-7}$ Children with hypertrophied adenoids, tonsils and inferior turbinates develop long face syndrome in 30 percent of cases studied. In contrast, children who have normal respiratory airways develop long face syndrome only 2 percent of the time. ${ }^{8}$ 
Schlenker, et al., demonstrated that the chronic absence of active nasal respiration affected the growth of the skull in experimental dogs. ${ }^{9}$ McNamara suggests malocclusions are adaptations to the changes in craniofacial muscular demands and their responses that naturally occur after the changed breathing pattern. ${ }^{10}$ Harvold and associates found that by inducing oral respiration in primates, certain functional and anatomical changes were likely to occur. They postulated that the morphological changes that gradually followed the functional adaptations were in response to differences in muscle recruitment associated with the change in mode of respiration. Researchers concluded, despite the identical nature of the stimulus, the structural changes depended upon the unique neuromuscular adaptation of the individual monkey. ${ }^{11}$

A Similar effect occurs in humans in that a variety of skeletal and dental configurations are observed as a result of oral respiration. Thus, these changes may be presumed to be the sequela of the neuromuscular adjustments required to maintain adequate respiratory function. ${ }^{12}$ Detractors of the theory use this variable response to oral respiration to deny the existence of any correlation between mode of respiration and effect on craniofacial development.

In a subjective evaluation of 1,033 children, Humphrey and Leighton reported an approximately equal distribution of malocclusions in nose and mouth breathers. In addition, they observed that of those children that kept their mouths open, almost half respired nasally. ${ }^{13}$ Kingsley and others felt that the V-shaped maxilla and deep palate are of genetic etiology and are not related to mouth breathing. Gwynne-Evans and Ballard subjectively evaluated the relationship between facial morphology and mode of respiration over a period of 15 years. They reported that orofacial morphology remains 
constant during growth, regardless of breathing patterns. They also stated "mouth breathing does not produce deformities of the jaws and malocclusions and does not result in the development of the adenoidal facies." ${ }^{14}$ Leech examined the relationship between lip competence and mode of breathing in subjects undergoing evaluation in a research clinic for upper respiratory disease. He found that fewer than one third of the lip incompetent persons were mouth breathers. ${ }^{15}$ Hartgerink found that impaired respiratory function can be found in patients with a variety of facial types. ${ }^{16} \mathrm{O}$ 'Ryan et al. concluded that they were unable to show that mouth breathing was of etiologic significance in the development of long-face syndrome. ${ }^{17}$

Most studies that deny the relationship between oral breathing and abnormal craniofacial development were conducted in the 1950's and 1960's. Recently, a study by Shanker using rhinomanometry found no correlation between mode of breathing and face type. In addition, it was found that some patients switch modes of respiration. ${ }^{18}$

The one piece of evidence that seems to bridge the gap between these opposing school's of thought is the lack of any clear definitions on mode of respiration, and more importantly the amount of the predominate mode. Until the amount of the predominant mode of respiration is objectively quantified, the debate will continue. Vig has echoed this observation by calling for more objective studies with unambiguous criteria to further our understanding on this complex issue ${ }^{19}$ This study marks an attempt to objectively measure the effects of RME on the nasal cavity volume and nasal airway resistance.

\section{Limitations of Two Dimensional Analysis}

One of the major barriers to understanding the respiratory effects of RME is the lack of documented correlation between increments of dental arch expansion and the 
associated minimum effective cross-sectional area of the nasal cavity. It is relatively easy to measure intermolar or intercanine width changes, however, these cannot be extrapolated to yield valid airway dimensions. The complex anatomy and superimposition of structures of the airway in frontal radiographs makes determination of the site of greatest constriction difficult. ${ }^{16,20-21}$ The lateral radiograph as a diagnostic tool for airway patency has proven to be no better. A weak relationship was found between adenoid size and nasal airway resistance. ${ }^{22}$ Investigators have proposed that the two dimensional view of the three dimensional airway is not an accurate means of measurement. ${ }^{19,23}$

\section{Three Dimensional Analysis}

Recent technological advancements have made 3-dimensional imaging possible at dental appointments. The NewTom $9000^{\mathrm{TM}}$ imaging system produced in Italy received FDA approval in April of 2001. Designed to image the maxillofacial region, the NewTom $9000^{\mathrm{TM}}$ employs the principle of tomosynthesis and is known as cone beamed CT. ${ }^{24}$ The NewTom $9000^{\mathrm{TM}}$ images are anatomically true, 3-dimensional representations from which electronically generated slices can be displayed from any angle. The radiation exposure to the patient is as low as $50 \mu \mathrm{Sv}$, which is similar to a full mouth periapical series. ${ }^{25}$

\section{Rhinomanometry}

Objective methods of testing nasal function in terms of airflow and related properties can be achieved by rhinomanometry. Rhinomanometry is a method resulting in a parameter known as nasal airway resistance (NAR), which has been used in the 
diagnosis of nasal obstruction for more than two decades ${ }^{26}$. Research has shown it to correlate closely with symptoms of nasal obstruction, and it has demonstrated minimal individual variation on repeated testing over a course of several weeks ${ }^{27}$.

Nasal resistance is calculated from the parameters of pressure and airflow during breathing by means of an equation modified from Ohm's Law ${ }^{28}$ :

$$
\begin{aligned}
& \text { Nasal Airway Resistance }(\mathrm{NAR})=\frac{\text { Transnasal Pressure Difference }}{\text { Airflow in } \mathrm{ml} / \mathrm{s}}=\frac{\Delta \mathrm{P}}{\mathrm{V} / \mathrm{Sec}} \\
& \text { Units: }- \text { Pressure }=\text { Pascals }
\end{aligned}
$$

\section{-Airflow Volume=millileters/second}

The active anterior rhinomanometry (AAR) method is unique in that both nasal passages are measured separately. The single pressure sensor measures one nostrils pressure difference while the nasal mask simultaneously measures the volume of airflow in the contra lateral nostril. The nasal passage acts as an extended tube and assumes the airway pressure of the nasopharynx equals the pressure at the naris of the nontested side. The total nasal airway resistance can then be calculated from 2 unilateral measurements. ${ }^{29}$ A disadvantage with AAR is that a complete unilateral obstruction such as a septal deviation will prevent measurement of $\mathrm{NAR} \cdot{ }^{30} \mathrm{~A}$ septal perforation also makes rhinomanometric measurements impossible. ${ }^{31}$ 


\section{MATERIALS AND METHODS}

The method in determining the nasal cavity volume was established by Dr. Jon Robinson. Nasal cavity volume data from 17 of the 27 patients are from Dr. Robinson's research. The same method of nasal cavity volume determination was used for the 10 additional patients (16 females and 11 males ages 9-18) enrolled in the study.

\section{Subject Selection}

Subjects for the study were orthodontic patients treated at the Loma Linda School of Dentistry, Department of Orthodontics, Graduate Orthodontic Clinic who required Rapid Maxillary Expansion (RME) as part of their comprehensive orthodontic treatment.

\section{Subject Inclusion Criteria}

1. Systemically healthy individuals between 5-19 years of age.

2. Orthodontic patients with a maxillary skeletal transverse insufficiency and requiring rapid palatal expansion as determined by the clinical and radiographic evaluation.

3. Patients who did not require surgically assisted rapid palatal expansion and/or orthognathic surgical correction.

4. Patients who were not pregnant.

\section{Subject Exclusion Criteria}

1. Patients who displayed no radiographic evidence of sutural separation following completion of the RME procedure.

2. Patients who failed to activate the RME device and therefore experience inadequate expansion to attain the treatment objective of RME. 
3. Patients with a complete unilateral nasal blockage, septal perforation, or inability to breathe properly into the rhinomanometer mask.

\section{Study Design}

As part of the diagnosis and treatment planning phase of the patients orthodontic treatment a full set of records was obtained. This included: frontal, lateral, and selected periapical x-rays, facial and intra-oral photographs, models mounted in centric relation, a NewTom $9000^{\mathrm{TM}}$ image scan, comprehensive clinical exam, and Rhinomanometric analysis. A hyrax expander anchored to the first bicuspids and first molars with orthodontic bands was used to accomplish the RME. The patients were instructed to activate the appliance at a rate of $0.4 \mathrm{~mm}$ per day. Patients were seen once a week until attending and resident determined that the expansion was sufficient. This protocol was generally in accordance with standard protocols for RME; lingual cusps of the permanent maxillary first molars should be vertically aligned with the buccal cusps of the permanent mandibular first molars (figure 1). At completion of expansion, the hyrax activation screw was locked in place by orthodontic ligature wire, linear expansion measured (figure 2) and post expansion records were then taken. Post expansion records consisted of a NewTom $9000^{\mathrm{TM}}$ image scan and rhinomanometric analysis. The hyrax appliance was left in place for an additional 4-6 month retentive period. 


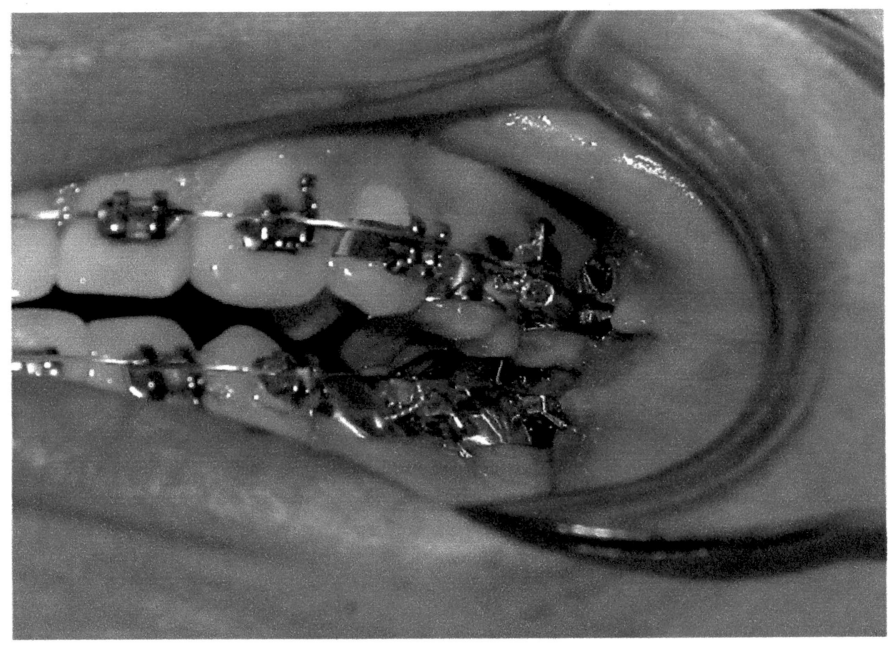

Figure 1. Vertical alignment of maxillary and mandibular working cusp tips.

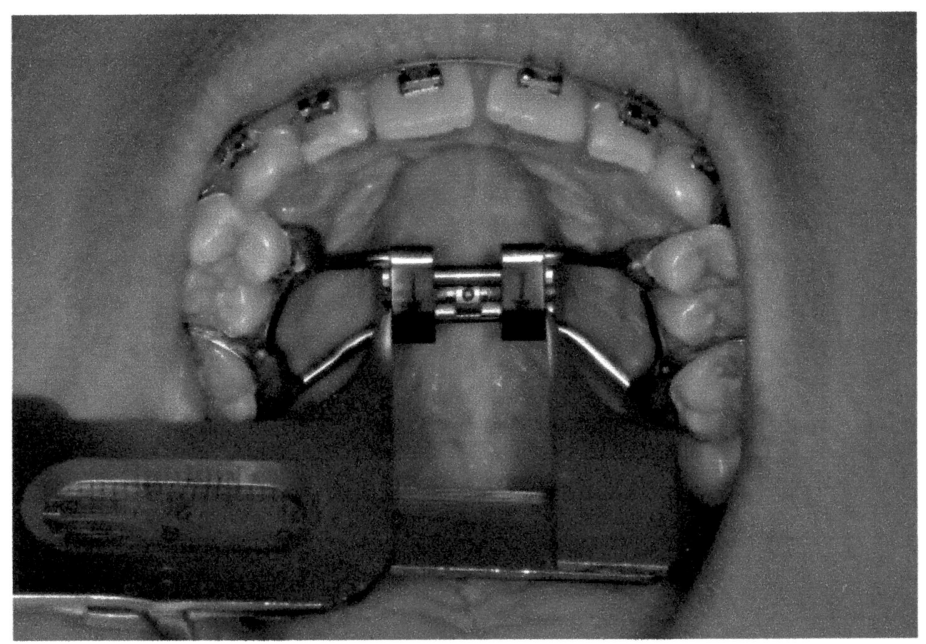

Figure 2. Measurement of linear expansion with boley gauge.

\section{Method of Determining Volumetric Change of Nasal Cavity}

The method used to measure the change in volume that occurs in the nasal cavity before and after RME was developed by Dr. Jon Robinson in his graduate research study. The following is a synopsis of the methods: 


\section{Measurements}

Nasal cavity volumes for each subject were generated using 3-D Doctor ${ }^{\mathrm{TM}}$ (Able Software, Lexingtion, Ma) a three-dimensional volume rendering software program. All 3-D Doctor ${ }^{\mathrm{TM}}$ volumetric measurements were computer generated to the nearest hundredth of a cubic centimeter. In order to assess the changes that occurred in nasal cavity volume when rapid maxillary expansion was carried out on orthodontic patients, it was necessary to first define the nasal cavity and then establish a method to measure the volume of this region before and after completion of the expansion procedure.

\section{Boundaries of the Nasal Cavity}

Due to the limited volume of the NewTom $9000^{\mathrm{m}}$, the nasal cavity was defined as the airway space that fell within the following boundaries:

i. Lateral boundary - the lateral walls of the nasal cavity.

ii. Medial boundary - the medial walls of the nasal cavity.

iii. Inferior boundary - a horizontal, transverse plane passing through the anterior nasal spine of the maxillary bone and the posterior nasal spine of the palatine bone, extending to the posterior aspect of the inferior nasal concha (Figure 3).

iv. Superior boundary - a plane that lies $30 \mathrm{~mm}$ superior to and parallel with the inferior boundary, and extending from the anterior boundary to the posterior boundary (Figure 3). 


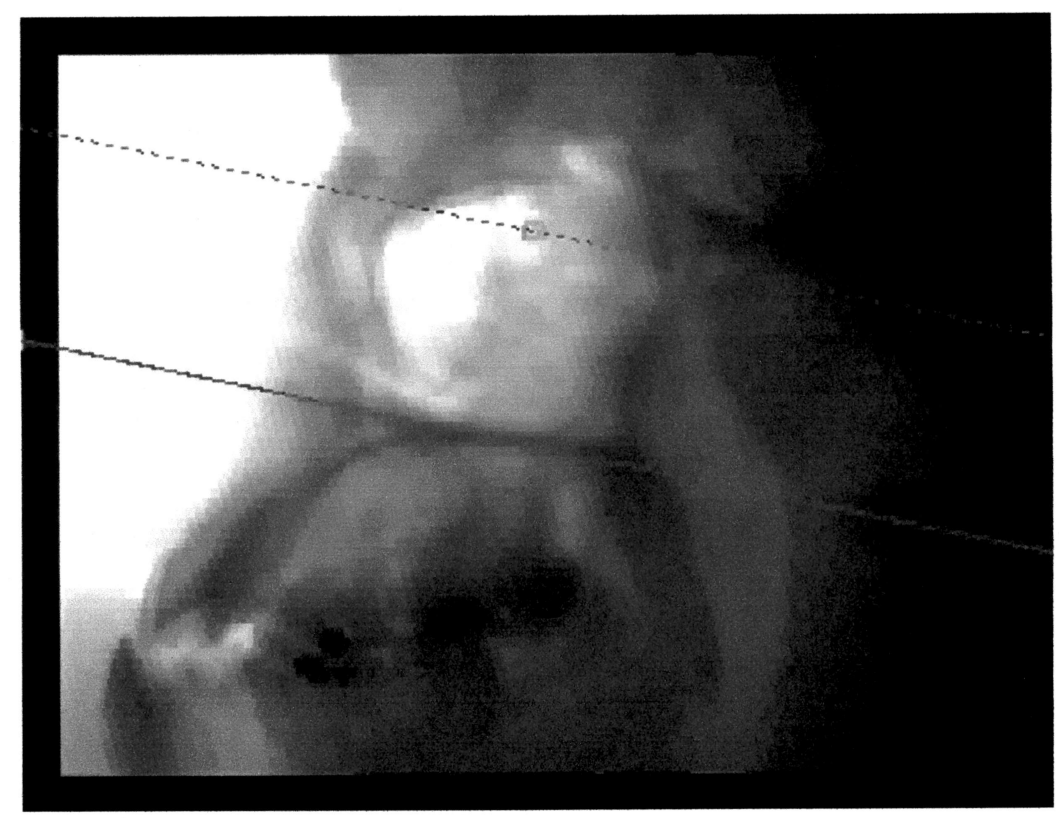

Figure 3. Inferior (solid) and superior (dashed) boundary of nasal cavity.

v. Anterior boundary - a plane perpendicular to the inferior boundary, that passes through the inferior, anterior aspect of the left and right maxilla where they define the borders of the anterior nasal aperture (Figure 4).

vi. Posterior boundary $-\mathrm{a}$ plane passing through the posterior aspect of the inferior nasal concha, perpendicular to the inferior boundary, and parallel with the anterior boundary (Figure 4). 


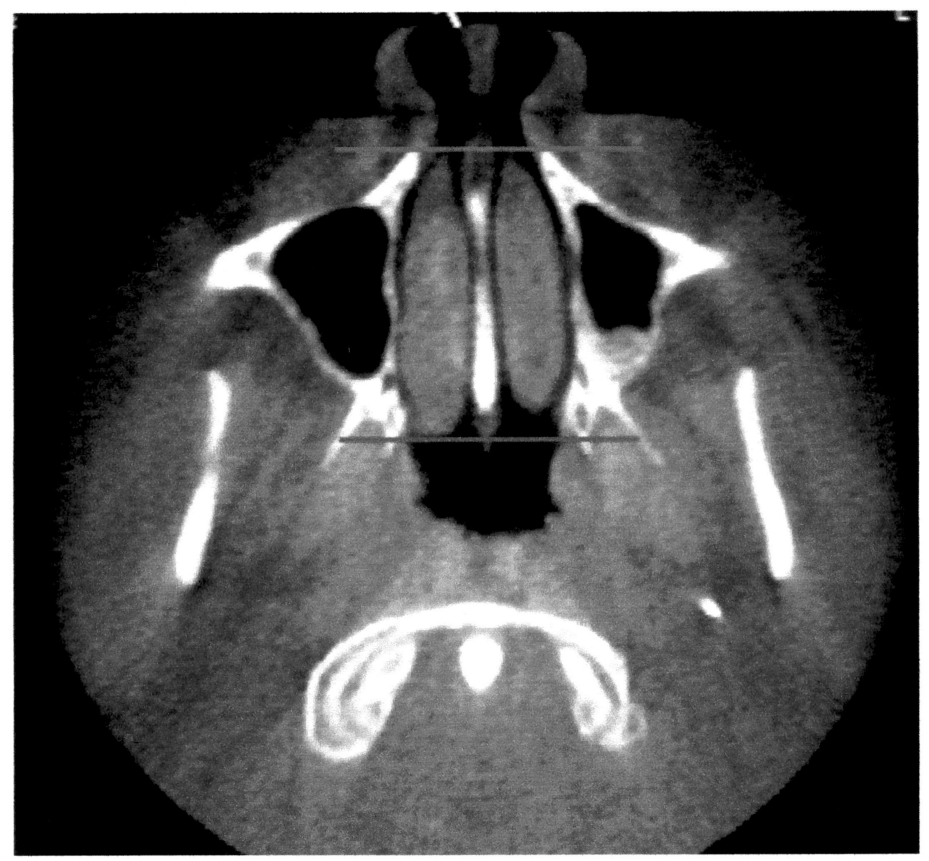

Figure 4. Anterior (yellow) and posterior (green) boundary of nasal cavity.

\section{Management of Tomographic Images}

All transaxial images falling within the boundaries of the defined nasal cavity were then extracted in series from anterior to posterior and saved as a sequence of bitmap images in the subject's digital file. The number of extracted coronal slices varied depending upon the antero-posterior dimensions of each subject's nasal cavity (figure 5). 

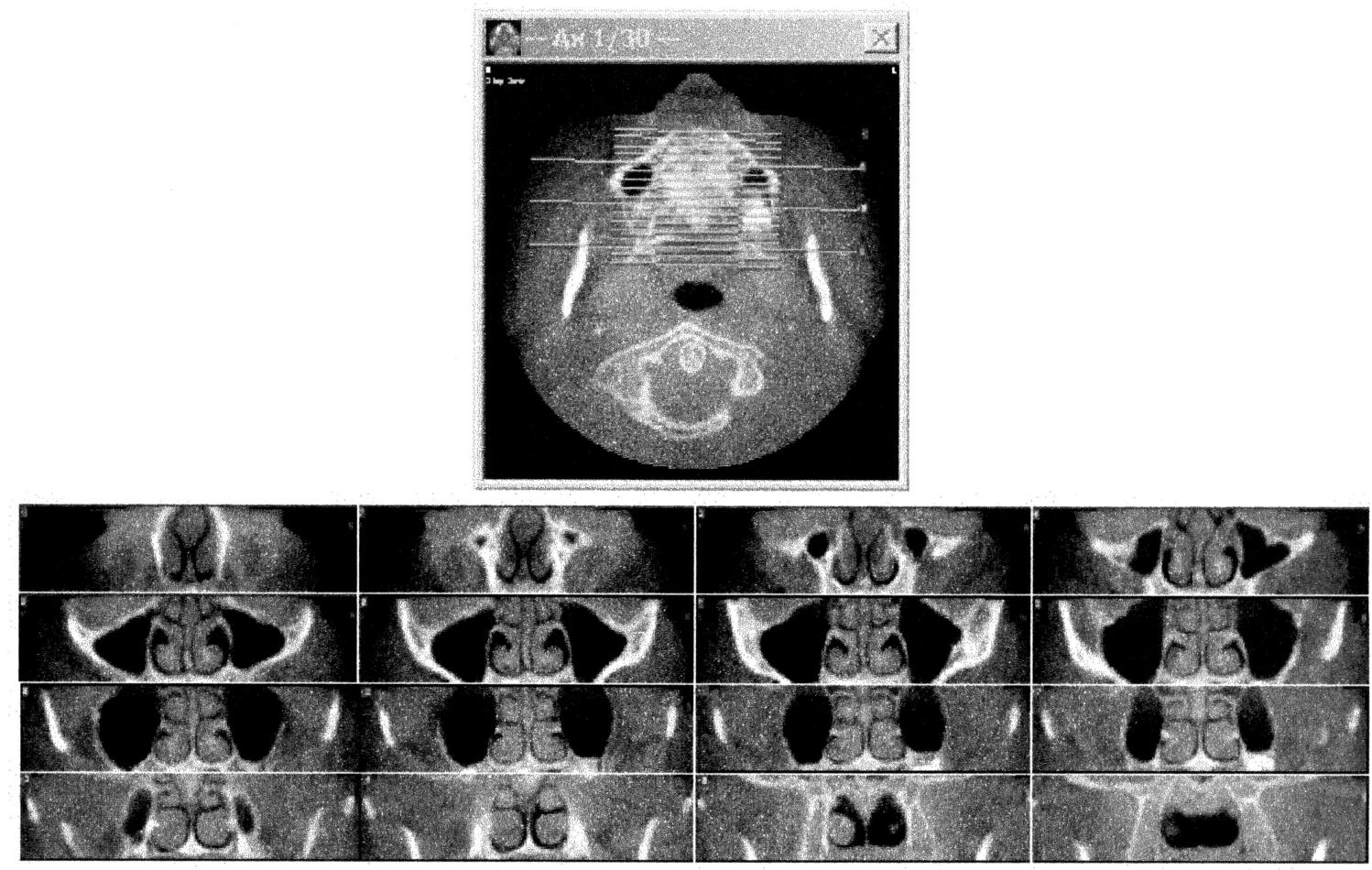

Figure 5. Sequential series of coronal tomographic slices

In order for 3-D Doctor ${ }^{\mathrm{TM}}$ to accurately analyze nasal cavity volume from the NewTom $9000^{\mathrm{TM}}$ study of each subject, it was necessary to create high-contrast images from the stored tomographic slices. To accomplish this, the sequences of transaxial images were hand traced, imported into Photoshop ${ }^{\mathrm{TM}}$, and the airway rendered as absolute black (figure 6). 

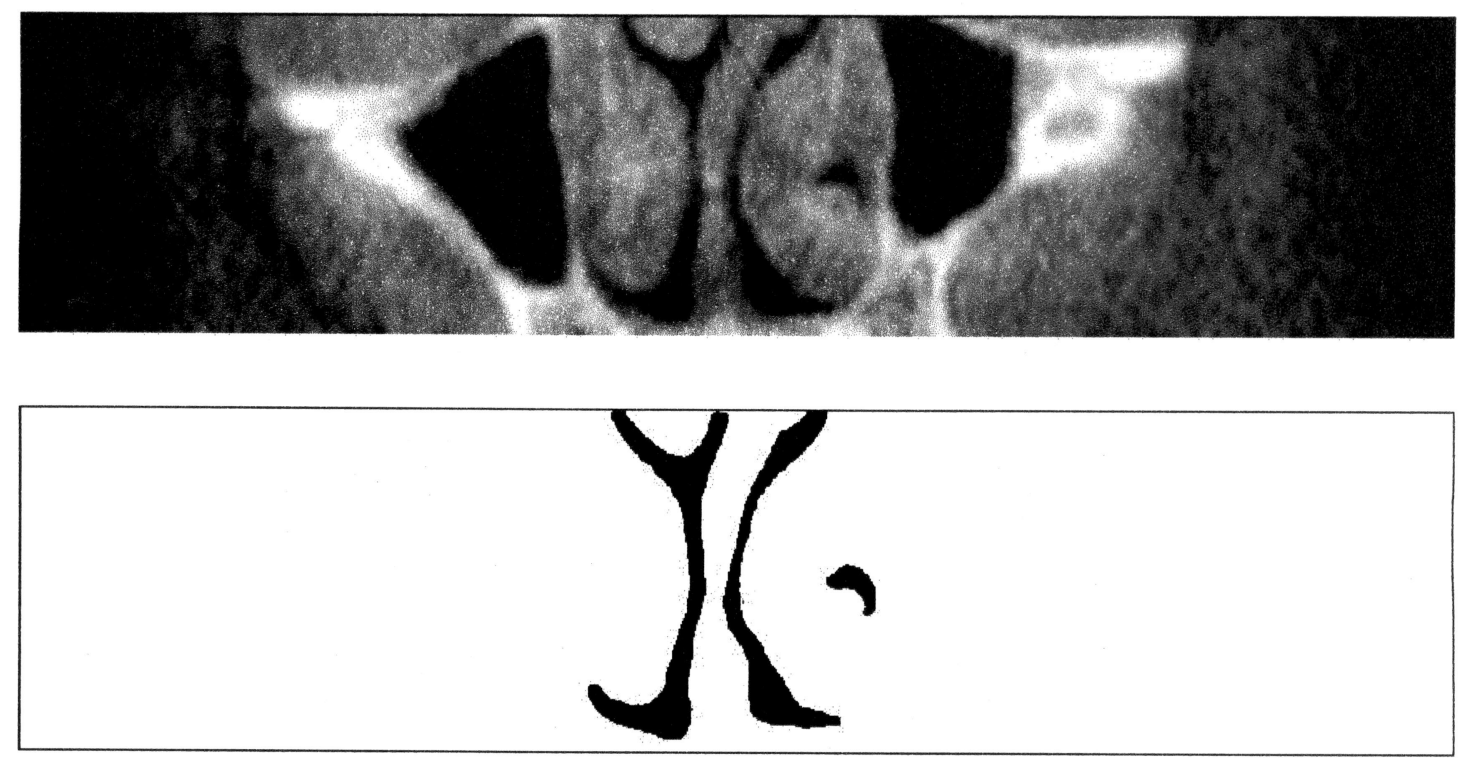

Figure 6. Coronal tomographic slice converted to absolute value image.

The high-contrast images were then sequentially imported into 3-D Doctor ${ }^{\mathrm{TM}}$

In 3-D Doctor ${ }^{\mathrm{TM}}$, the images were then "stacked" from anterior to posterior to create the nasal cavity volume rendering (figures 7-12).

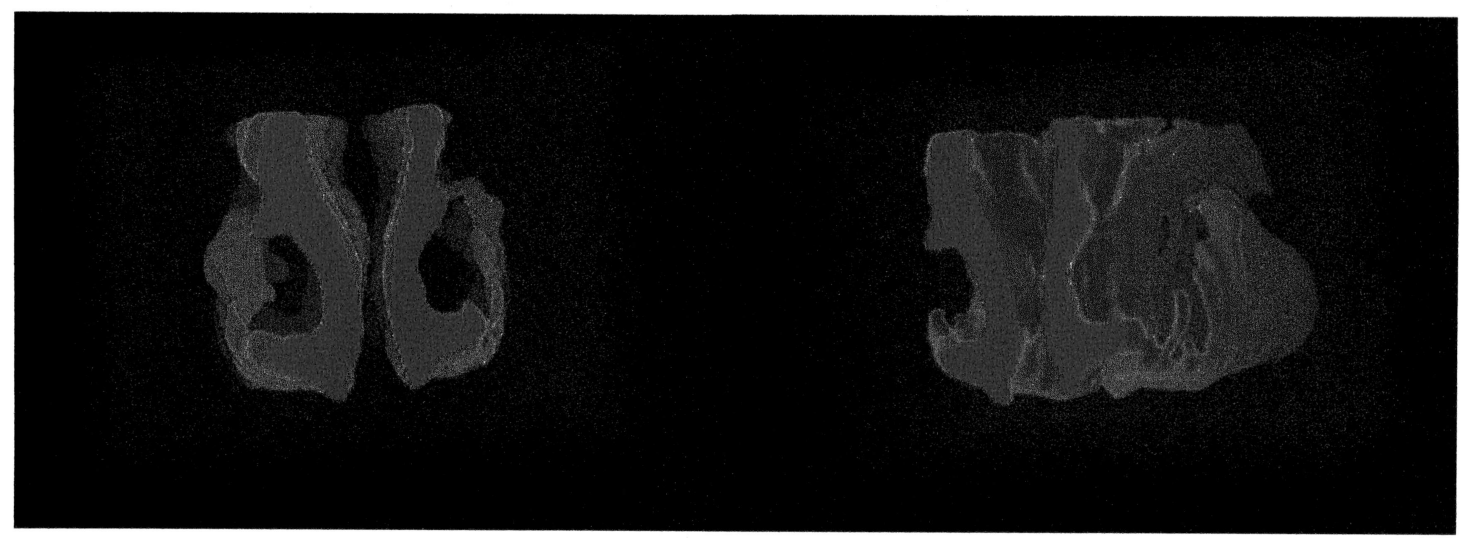

Figure 7. Anterior aspect of nasal cavity volume rendering.
Figure 8. Left oblique aspect of nasal cavity volume rendering. 


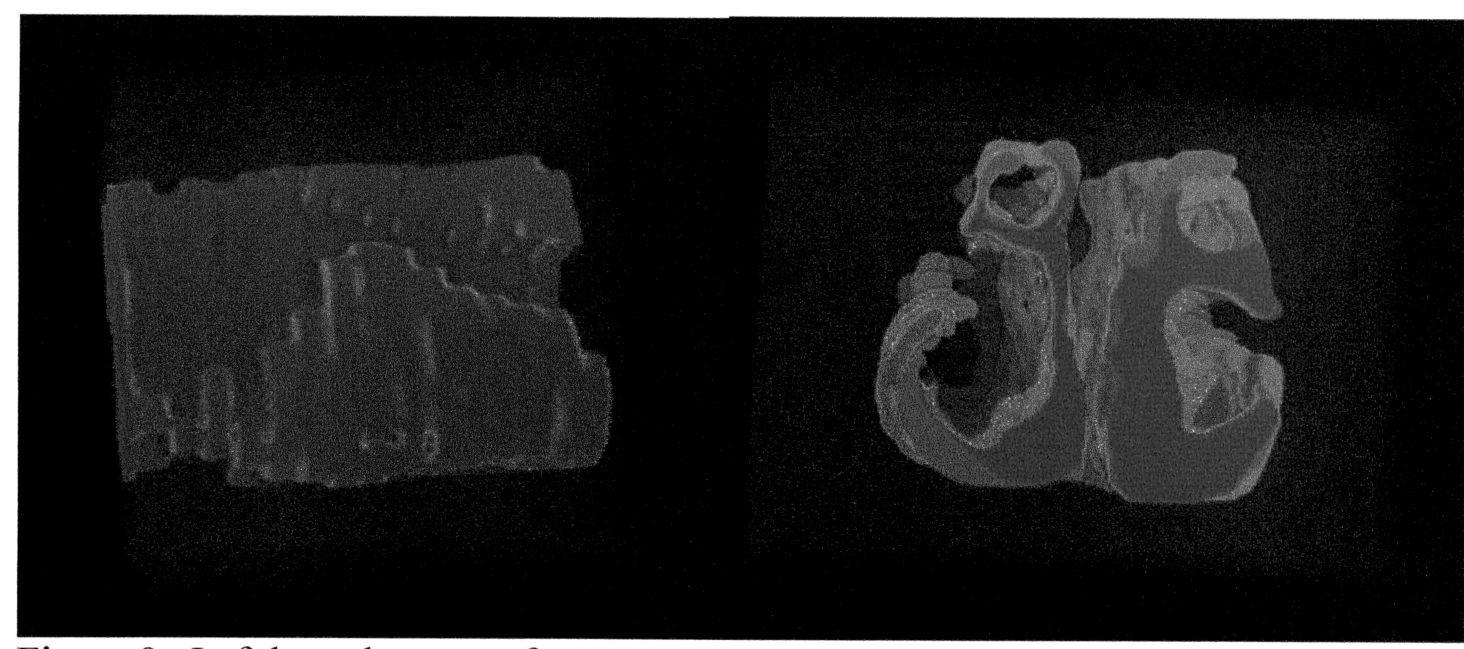

Figure 9. Left lateral aspect of nasal cavity volume rendering.
Figure 10. Posterior aspect of nasal cavity volume rendering.

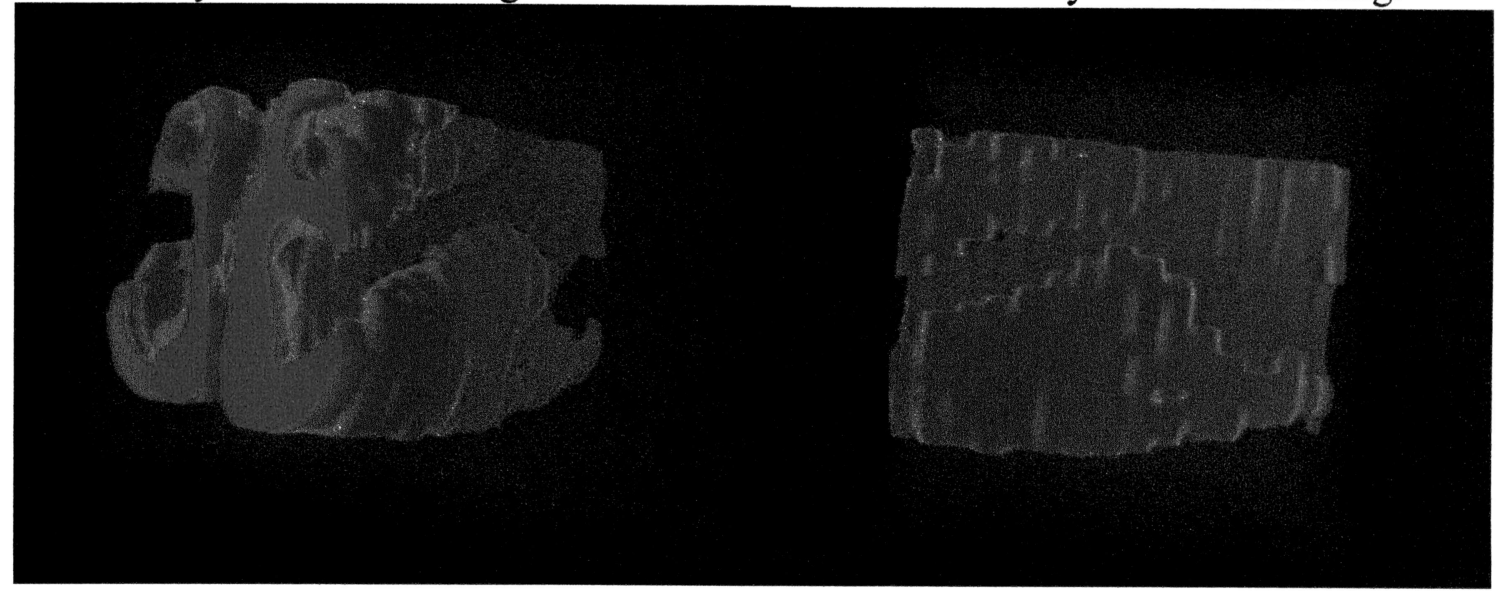

Figure 11. Right oblique aspect of nasal cavity volume rendering.
Figure 12. Right lateral aspect of nasal cavity volume rendering.

\section{Rhinomanometric Analysis}

Active Anterior Rhinomanometry technique was used for it's ease of use and reproducibility. ${ }^{32-33}$ No nasal decongestant was administered to patients, because a natural physiologic NAR without the benefit of decongestant was desired, similar to Jones's and Timms's studies, respectively. ${ }^{34-35}$ In addition, a previous study demonstrated only a $5.3 \%$ difference in NAR when using decongestant four months after RME. ${ }^{36}$ 
Patients were instructed to "blow nose" with tissue paper and then a visual inspection for any obstruction was performed. The pressure catheter was then attached to one nostril with medical adhesive tape. Care was taken to ensure an airtight seal around the catheter, any leakage would result in lower than actual NAR readings. The flow mask was then held firmly in place covering the nose and mouth. Another inspection to ensure an airtight seal around the mask was conducted, any leakage at this interface would result in a higher than actual NAR. The patient was then instructed to sit in an upright position and to breathe comfortably with the mouth closed. The test was then initiated, five to ten respiratory cycles were recorded and saved onto the computer. The test was then repeated on the opposite nostril and the nasal airway resistance calculated.

\section{Determination of Facial Type}

The patient's facial type was determined by three cephalometric measurements. Total face height, mandibular plane angle, and facial axis from the pre expansion records were used in the diagnosis. The three measurements were given equal weighting. Each standard deviation away from normal was assigned a point. If the deviation was on the brachyfacial side a positive value was assigned, a deviation on the dolichofacial side was assigned a negative value. The individual point values for each measurement were then combined to give one value. If the combined value was positive then patient was diagnosed as brachyfacial, a negative combined value was diagnosed as dolichofacial, and if there was no positive or negative value then patient was diagnosed as mesofacial. 


\section{RESULTS}

\section{Statistical Analyses}

Data for nasal cavity volume, amount of linear expansion, and nasal airway resistance was subjected to Pearson's analysis in an effort to find any linear correlations among these continuous variables, see table 2 for descriptive summary of all continuous variables. Scatter plot diagrams with regression lines were constructed using the selected variables to create an image of possible data clusters. Dependent $t$ - tests were utilized to test if the pre RME nasal cavity volume data was significantly different to the post-RME nasal cavity volume data. The pre-expansion NAR and post-expansion NAR data sets were examined with the dependent $t$-test as well. In an effort to find a relationship between an individual's face type and any of the continuous variables, the ANOVA analysis was applied to the data. A Post-Hoc Analysis followed to identify the location of differences among the variables.

\section{Descriptive Statistics of Continuous Variables}

The amount of linear expansion ranged from a minimum of $4.0 \mathrm{~mm}$ to a maximum of $11.4 \mathrm{~mm}$ and a mean value of $6.7 \mathrm{~mm}$. All subjects in study had an increase in nasal cavity volume after RME. The mean amount of nasal cavity volume change was $2.6 \mathrm{~cm}^{3}$, which correlates to a $36.8 \%$ mean increase in nasal cavity volume. 24 out of the 27 subjects did have a reduction in NAR. Overall the NAR had a mean decline of .317 $\mathrm{Pa}^{*} \mathrm{~s} / \mathrm{ml}$, which correlates to a $36.4 \%$ mean decrease in resistance. A summary of all the continuous variables is shown in Table 1. 


\begin{tabular}{|c|c|c|c|c|c|}
\hline & N & Minimum & Maximum & Mean & Std. Deviation \\
\hline mm of Expansion & 27 & 4.0 & 11.4 & 6.7 & 1.9 \\
\hline Volume Pre-Expansion & 27 & 4.6 & 10.2 & 7.6 & 1.5 \\
\hline Volume Post-Expansion & 27 & 5.8 & 15.9 & 10.2 & 2.2 \\
\hline Change in Volume & 27 & 0.1 & 6.7 & 2.6 & 1.8 \\
\hline \% Change in Volume & 27 & 1.3 & 144.6 & 36.8 & 30.4 \\
\hline Pre-Expansion Nasal Airway Resistance & 27 & 0.26 & 2.26 & 0.71 & 0.44 \\
\hline Post-Expansion Nasal Airway Resistance & 27 & 0.08 & 0.88 & 0.39 & 0.21 \\
\hline Change in Nasal Airway Resistance & 27 & -1.53 & 0.23 & -0.31 & 0.36 \\
\hline \% Change in Nasal Airway Resistance & 27 & -82.1 & 38.0 & -36.4 & \\
\hline
\end{tabular}

Table 1. Descriptive statistics for all continuous variables.

\section{Dependent $t$-Tests}

The mean values for both nasal cavity volume and NAR when comparing the before RME and after RME were statistically different (nasal cavity volume-dependent $t=7.38, \mathrm{p}=<.001 ; \mathrm{NAR}-$ dependent $t=4.48, \mathrm{p}=<.001)$. Box whisker plots were constructed to graphically illustrate these differences, see Figures 13 and 14, respectively. 


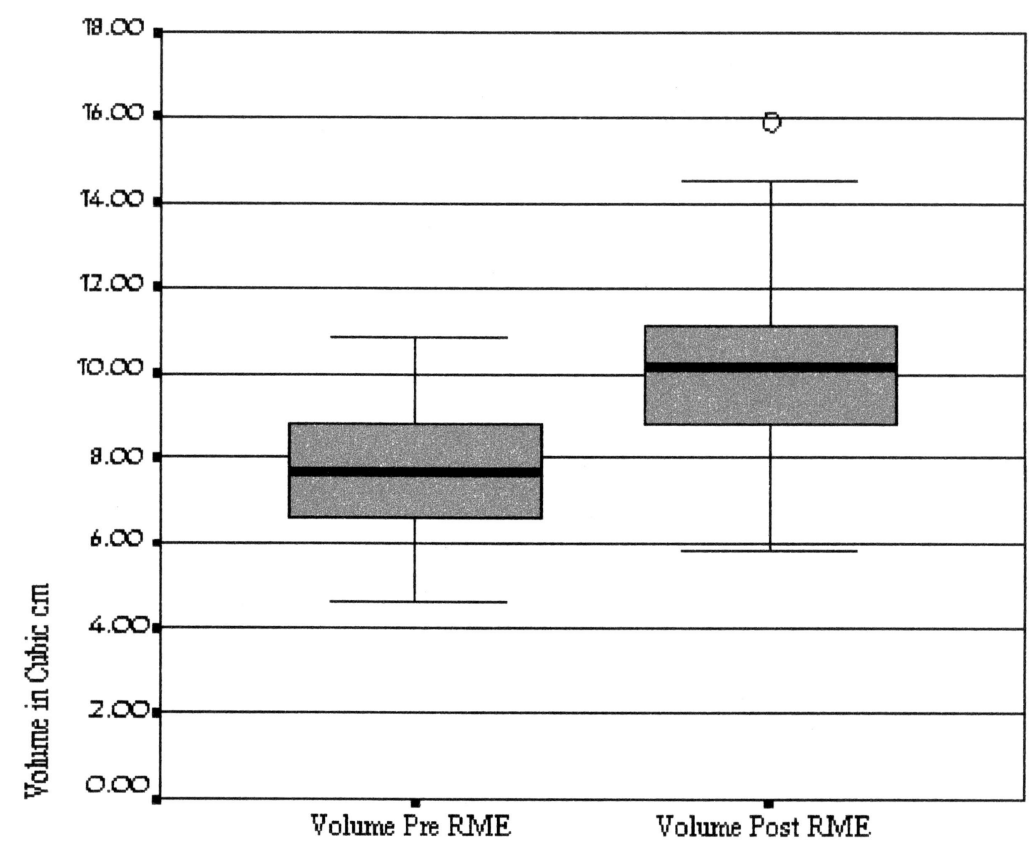

Figure 13. Box whisker: Volume before and after RME.

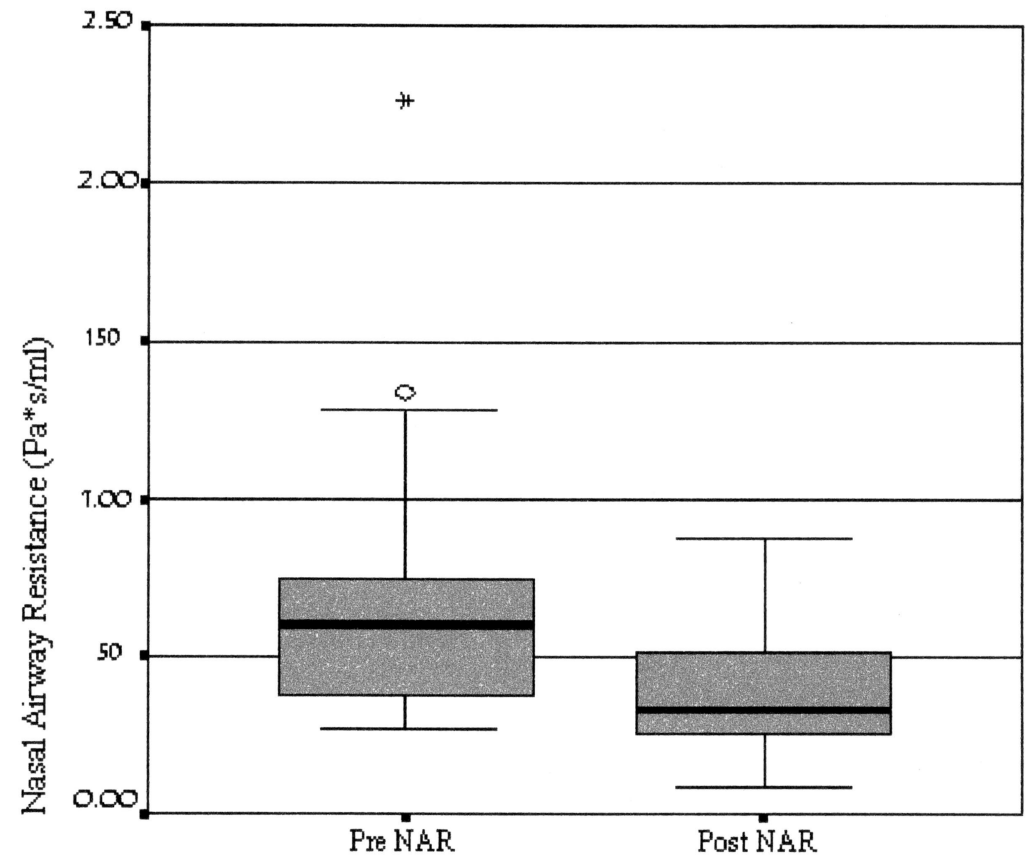

Figure 14. Box whisker: NAR before and after RME 


\section{Pearson's Analysis}

The Pearson's analysis yielded a low correlation coefficient between change in NAR and change in volume, $r=.26$ with a $P$ value of .19 . Several correlations that are worth mentioning: Change in Volume (\%) with Volume ${ }_{11}$ shows an inverse relationship, in other words individuals with a small pre expansion nasal cavity volume are expected to have a relatively large increase in nasal cavity volume post expansion. The same inverse relationship exists between change in NAR and NAR pre expansion. In essence, individuals with a high nasal airway resistance prior to expansion therapy can be expected to have a relatively large decrease in nasal airway resistance after expansion therapy. The Pearson's analysis of all the continuous variables is summarized in Table 2. Scatterplots of selected continuous variables were constructed to elucidate any data clusters that the statistical analyses did not reveal. Pre expansion NAR vs. change in NAR, volume pre expansion vs. \% change in volume, pre expansion NAR vs. \% change in NAR, change in NAR vs. change in volume, and change in volume vs. linear expansion are illustrated in figures 15-18. 


\begin{tabular}{|c|c|c|c|c|c|c|c|c|c|c|}
\hline \multicolumn{2}{|c|}{$\begin{array}{c}\text { Pearson Correlation }=r \\
\text { Significance }=\mathrm{P} \\
\text { Number of subjects }=\mathrm{N}\end{array}$} & $\begin{array}{l}\text { Linear } \\
\text { Expan. } \\
(\mathrm{mm})\end{array}$ & $\begin{array}{l}\mathrm{Vol}_{\mathrm{T} 1} \\
\left(\mathrm{~cm}^{3}\right)\end{array}$ & $\begin{array}{l}\mathrm{Vol}_{\mathrm{T} 2} \\
\left(\mathrm{~cm}^{3}\right)\end{array}$ & $\begin{array}{l}\Delta \mathrm{Vol} \\
\left(\mathrm{cm}^{3}\right)\end{array}$ & $\begin{array}{c}\Delta \mathrm{Vol} \\
(\%)\end{array}$ & $\mathrm{NAR}_{\mathrm{t} 1}$ & $\mathrm{NAR}_{\mathrm{t} 2}$ & $\triangle N A R$ & $\triangle \mathrm{NAR}$ \\
\hline Volume $_{\mathrm{tl}}$ & $\begin{array}{l}r \\
\mathrm{P} \\
\mathrm{N}\end{array}$ & $\begin{array}{l}.11 \\
.58 \\
28\end{array}$ & & & & & & & & \\
\hline Volume $_{\mathrm{t} 2}$ & $\begin{array}{l}r \\
\mathrm{P} \\
\mathrm{N}\end{array}$ & $\begin{array}{l}.12 \\
.54 \\
28\end{array}$ & $\begin{array}{l}.59 \\
.001 \\
28\end{array}$ & & & & & & & \\
\hline$\Delta$ Volume $\left(\mathrm{cm}^{3}\right)$ & $\begin{array}{l}r \\
\mathrm{P} \\
\mathrm{N}\end{array}$ & $\begin{array}{l}.05 \\
.81 \\
28\end{array}$ & $\begin{array}{r}-.19 \\
.34 \\
28\end{array}$ & $\begin{array}{l}.68 \\
.001 \\
28\end{array}$ & & & & & & \\
\hline$\Delta$ Volume $(\%)$ & $\begin{array}{l}r \\
\mathrm{P} \\
\mathrm{N}\end{array}$ & $\begin{array}{l}.04 \\
.86 \\
28\end{array}$ & $\begin{array}{l}-.47 \\
.012 \\
28\end{array}$ & $\begin{array}{l}.40 \\
.034 \\
28\end{array}$ & $\begin{array}{l}.91 \\
.001 \\
28\end{array}$ & & & & & \\
\hline $\mathrm{NAR}_{\mathrm{tl}}$ & $\begin{array}{l}r \\
\mathrm{P} \\
\mathrm{N}\end{array}$ & $\begin{array}{l}15 \\
.451 \\
27\end{array}$ & $\begin{array}{l}.06 \\
.749 \\
27\end{array}$ & $\begin{array}{l}-.22 \\
.270 \\
27\end{array}$ & $\begin{array}{c}-.33 \\
.097 \\
27\end{array}$ & $\begin{array}{c}-.27 \\
.170 \\
27\end{array}$ & & & & \\
\hline $\mathrm{NAR}_{\mathrm{t} 2}$ & $\begin{array}{l}r \\
\mathrm{P} \\
\mathrm{N}\end{array}$ & $\begin{array}{l}.08 \\
.700 \\
27\end{array}$ & $\begin{array}{c}-.16 \\
.424 \\
27\end{array}$ & $\begin{array}{c}-.32 \\
.118 \\
27\end{array}$ & $\begin{array}{c}-.24 \\
.223 \\
27\end{array}$ & $\begin{array}{c}-.14 \\
.502 \\
27\end{array}$ & $\begin{array}{c}.59 \\
.001 \\
27\end{array}$ & & & \\
\hline$\triangle \mathrm{NAR}$ & $\begin{array}{l}r \\
\mathrm{P} \\
\mathrm{N}\end{array}$ & $\begin{array}{l}-.14 \\
.484 \\
27\end{array}$ & $\begin{array}{c}-.17 \\
.397 \\
27\end{array}$ & $\begin{array}{c}.09 \\
.643 \\
27\end{array}$ & $\begin{array}{l}.26 \\
.190 \\
27\end{array}$ & $\begin{array}{c}.26 \\
.198 \\
27\end{array}$ & $\begin{array}{c}-.89 \\
.000 \\
27\end{array}$ & $\begin{array}{c}-.15 \\
.462 \\
27\end{array}$ & & \\
\hline$\triangle \mathrm{NAR}(\%)$ & $\begin{array}{l}r \\
\mathrm{P} \\
\mathrm{N}\end{array}$ & $\begin{array}{c}-.12 \\
.560 \\
27\end{array}$ & $\begin{array}{c}-.30 \\
.132 \\
27\end{array}$ & $\begin{array}{c}-.14 \\
.484 \\
27\end{array}$ & $\begin{array}{l}.08 \\
.689 \\
27\end{array}$ & $\begin{array}{l}.14 \\
.500 \\
27\end{array}$ & $\begin{array}{c}-.42 \\
.028 \\
27\end{array}$ & $\begin{array}{c}.40 \\
.041 \\
27\end{array}$ & $\begin{array}{c}.74 \\
.000 \\
27\end{array}$ & \\
\hline
\end{tabular}

Table 2. Summary of Pearson's correlation analysis. T1= before RME, T2 = after RME. 


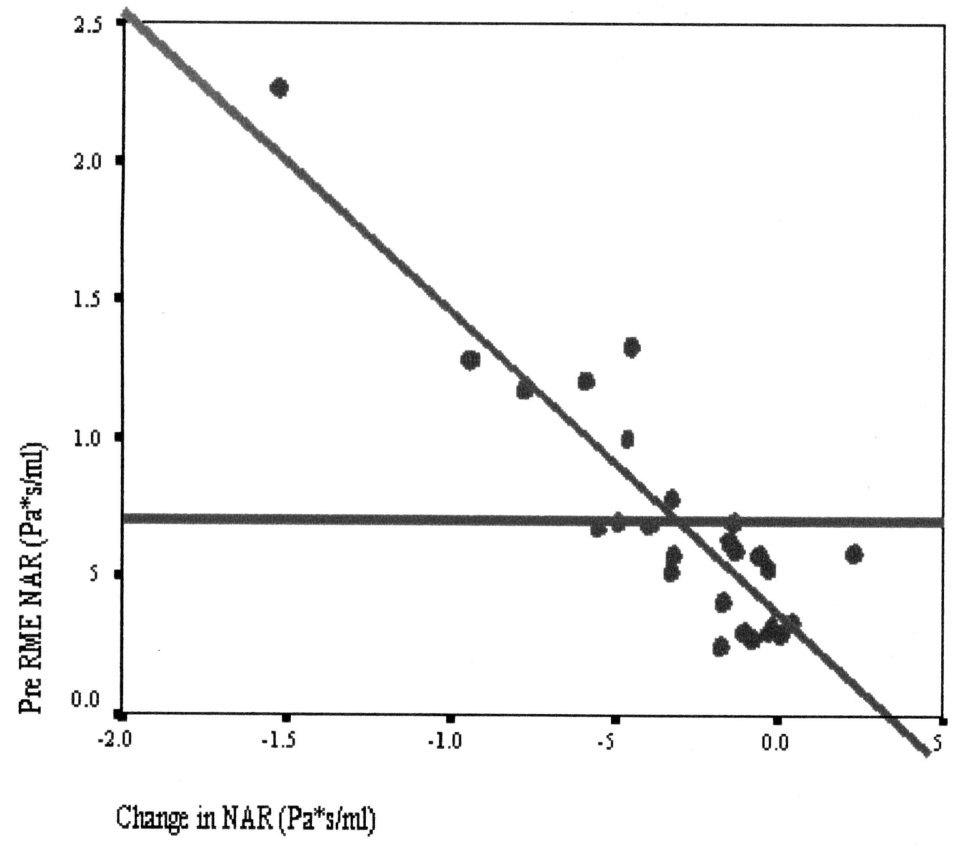

Figure 15. Scatterplot: Before RME NAR vs. Change in NAR. $r=-.89, \mathrm{P}=<.001$. This graphically shows the inverse relationship between the two variables; a high before expansion NAR correlates with a large change in NAR. The reason for the inverse relationship and negative $r$ is because 24 of the 27 subjects NAR had an absolute value decrease. Thus, the change in NAR variable has a negative value.

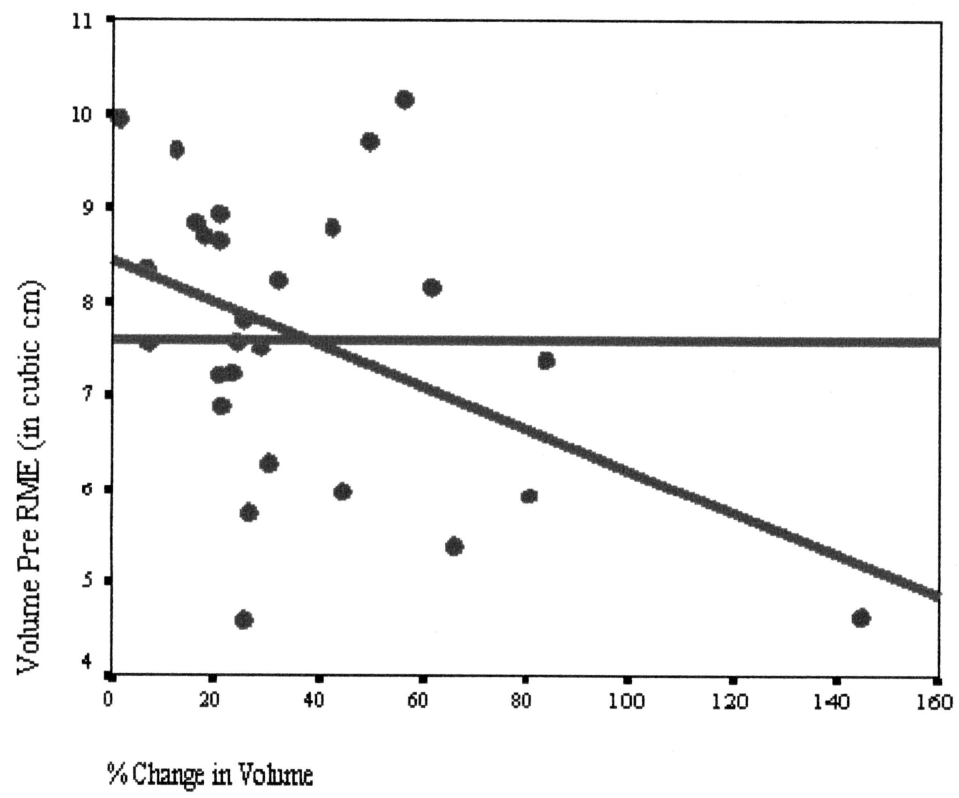

Figure 16. Scatterplot:Volume Pre RME vs. \% Change in Volume. $r=-.47, \mathrm{P}=.012$. The negative $r$ value and slope of the line indicates the inverse relationship between these variables. Individuals with a small volume before RME tend to have a high $\%$ change in volume after RME. 


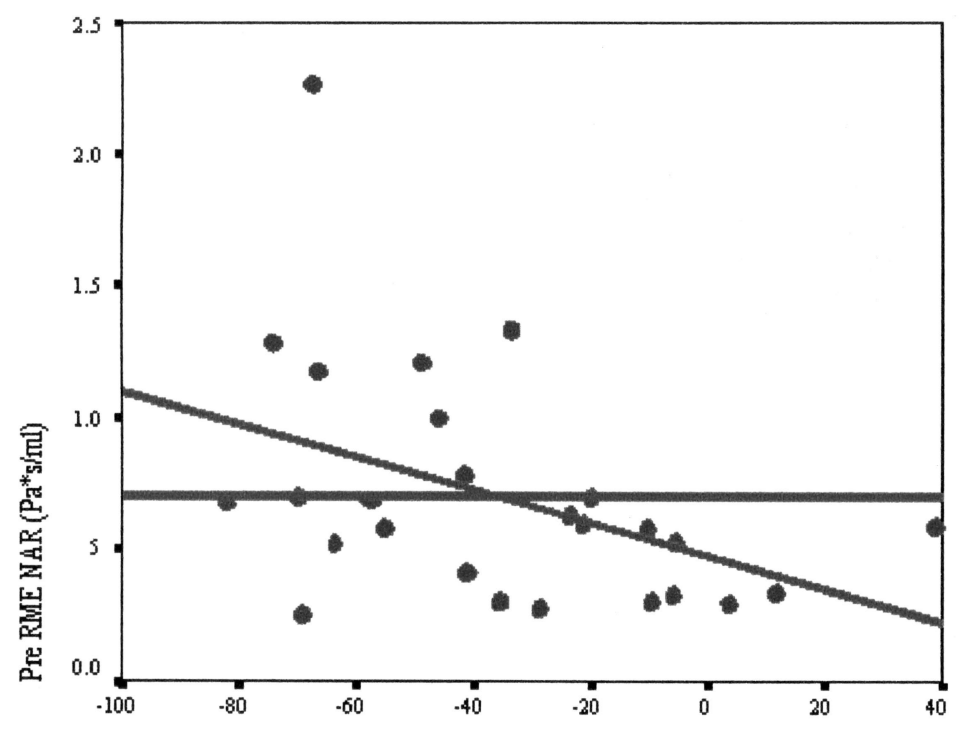

$\%$ Change in NAR

Figure 17. Scatterplot: Pre Expansion NAR vs. \% Change in NAR. $r=-.423, . \mathrm{P}=028$. Again, another inverse relationship between these variables.

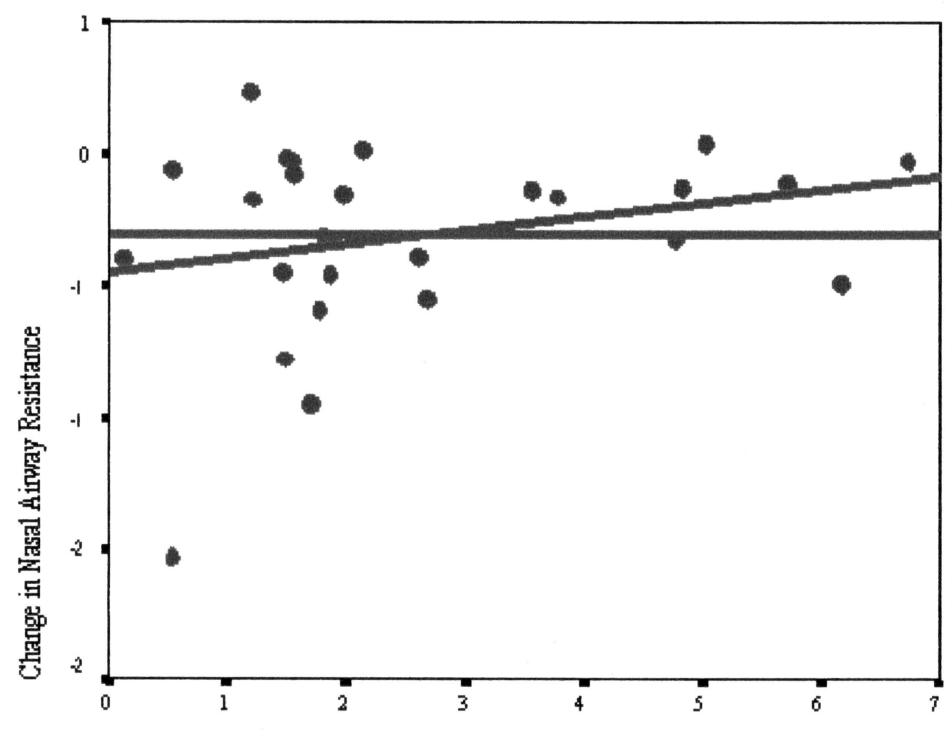

Change in Volume

Figure 18. Scatterplot: Change in NAR vs. Change in Volume $r=.26, P=.190$. The correlation between these variables was low. It appears the change in volume does not occur proportionally to the change in NAR. 


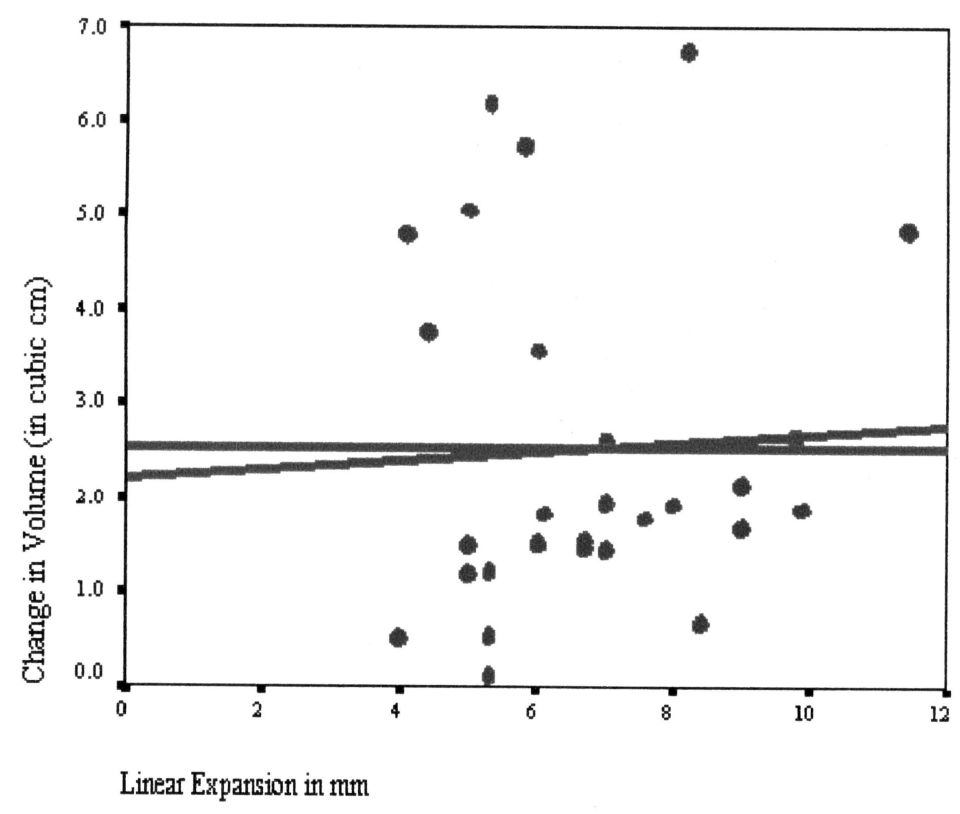

Figure 19. Scatterplot: Change in volume vs. linear expansion $(\mathrm{mm})$. Notice the cluster of data points in the $1.0-2.0 \mathrm{~cm}^{3}$ region.

\section{Face Type: ANOVA and Post Hoc Analyses}

The ANOVA test was applied to the data set to identify differences among face types. These analyses revealed a significant difference in the amount of reduction in NAR among the three face types. The most pronounced difference is that between Dolichofacial and Brachyfacial individuals, the Dolichofacial group experiencing a mean reduction of 33.7\% greater than the Brachyfacial group at a significance level of .014. The differences among the other face types were not as statistically significant, yet may have meaning in a clinical context. A summary of results from the ANOVA with corresponding Post Hoc and Box Whisker analyses are in Tables 3,4 and Figure 20 respectively. 


\begin{tabular}{|c|c|c|c|c|c|c|}
\hline \multicolumn{1}{|c|}{} & $\begin{array}{c}\text { Sum of } \\
\text { Squares }\end{array}$ & df & $\begin{array}{c}\text { Mean } \\
\text { Square }\end{array}$ & $F$ & Sig. \\
\hline \multirow{3}{*}{$\begin{array}{c}\text { \% Change in Nasal Airway } \\
\text { Resistance }\end{array}$} & Between Groups & 5288.010 & 2 & 2644.005 & 3.490 & .047 \\
\cline { 2 - 7 } & Within Groups & 18183.821 & 24 & 757.659 & & \\
\cline { 2 - 7 } & Total & 23471.831 & 26 & & & \\
\cline { 2 - 7 } & & &
\end{tabular}

Table 3. ANOVA. Continuous Variables by Face Type

\begin{tabular}{|c|c|c|c|c|c|c|c|}
\hline & & & & & & $\begin{array}{l}95 \% \text { Co } \\
\text { Inte }\end{array}$ & $\begin{array}{l}\text { fidence } \\
\text { val }\end{array}$ \\
\hline $\begin{array}{c}\text { Dependent } \\
\text { Variable }\end{array}$ & (I) Face Type & (J) Face Type & $\begin{array}{c}\text { Mean } \\
\text { Difference } \\
(I-J)\end{array}$ & $\begin{array}{l}\text { Std. } \\
\text { Error }\end{array}$ & Sig. & $\begin{array}{l}\text { Lower } \\
\text { Bound }\end{array}$ & $\begin{array}{l}\text { Upper } \\
\text { Bound }\end{array}$ \\
\hline \multirow{3}{*}{$\begin{array}{l}\% \text { Change in } \\
\text { Nasal Airway } \\
\text { Resistance }\end{array}$} & Brachyfacial & Dolichofacial & 33.7 & 12.7 & .014 & 7.4 & 60.0 \\
\hline & Mesofacial & Dolichofacial & 10.7 & 13.4 & .434 & -17.0 & 38.4 \\
\hline & Mesofacial & Brachyfacial & 23.0 & 15.3 & .147 & -54.6 & 8.6 \\
\hline
\end{tabular}

Table 4. Post-Hoc Test, LSD: Tukey's Least Significant Difference (no family-wise alpha correction). Significant difference in $\%$ change of NAR between brachyfacial and dolichofacial. 


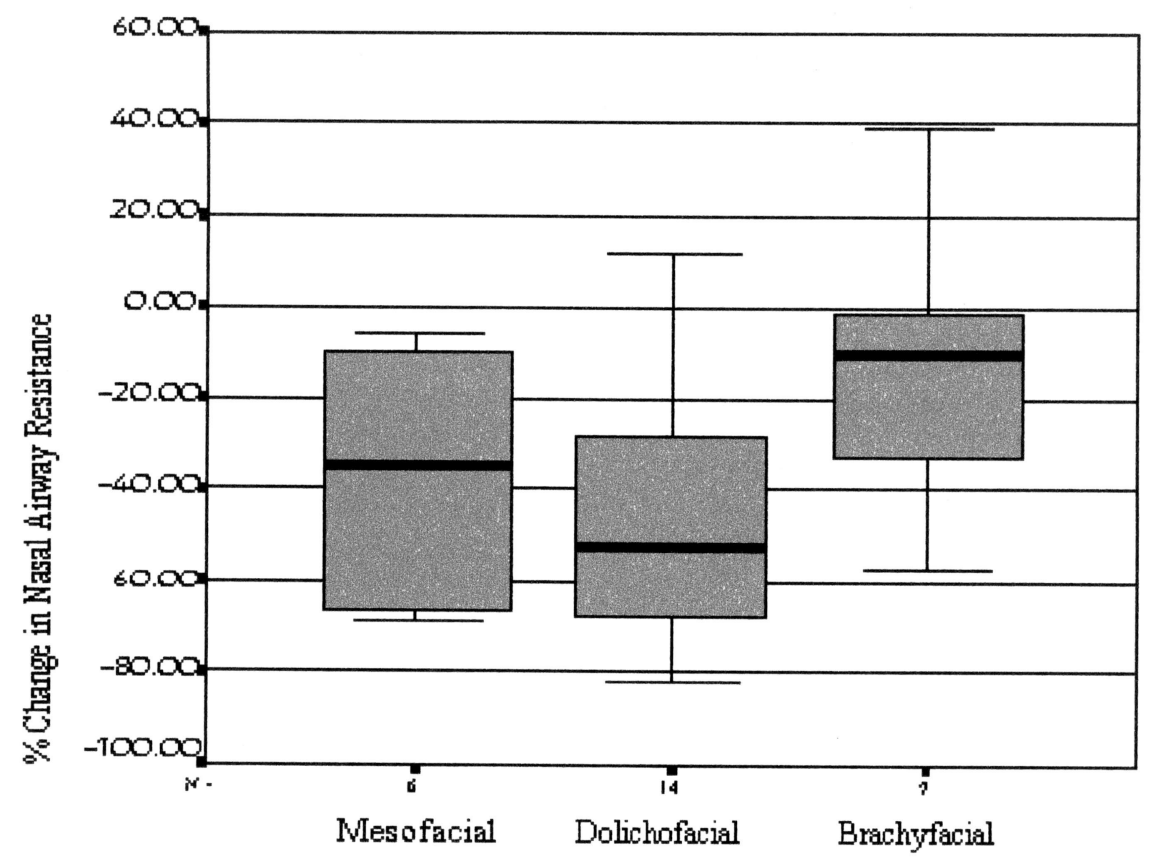

Face Type

Figure 20. Box Whisker: \% Change in Nasal Airway Resistance vs. Face Type 


\section{DISCUSSION}

The data from the Dependent $t$-Test makes it abundantly clear that RME does increase the nasal cavity volume and decrease the NAR.

The Pearson's analysis did not yield the intuitive correlation that was anticipated between the nasal cavity volume increase and a commensurate decrease in nasal airway resistance (Table 2). As a result of this, the data was re-examined for any possible nonlinear relationships between volume and NAR. A quadratic fit of the data points failed to reach any level of significance. Also, the relationship of airflow dynamics to that of resistance and dimensional change is not a direct one. According to Poiseuille's Law, laminar airflow varies with the fourth power of the radius; if the radius is doubled the flow would increase sixteen fold. ${ }^{37}$ Using this theory, the data was re-tested with the Pearson's analysis and Non-linear regression analysis. Neither of these tests improved the correlation between volume and NAR. This is most likely the result of the differences in laminar and turbulent airflow. When airflow becomes turbulent, its properties are very hard to predict. ${ }^{30}$ One of the primary physiologic functions of the nasal cavity is to create turbulent airflow for the impaction of particulates, heating of the air, and humidification ${ }^{38}$. In addition, obstruction can occur not only in the nasal cavity, but also in the nasopharynx, oropharynx, and laryngopharynx. Frequently, the obstruction occurs in more than one of these anatomical locations ${ }^{39}$. Thus, from this study, any statistically significant relationship between nasal cavity volume and NAR is unlikely. The complex intricacy of the nasal cavity anatomy and its effect upon airflow resistance appears to negate any linear effect of increased nasal cavity volume. 
From the data set, the most powerful correlation is before expansion NAR vs. change in NAR (see figure 15). Individuals with a high pre expansion nasal airway resistance can be expected to have the largest decrease in nasal resistance. However, this does not mean that the individual reaches a normal resistance level; some of these individuals still need referral to an Otolaryngologist for evaluation of turbinectomy, adenoidectomy or other procedures in order to achieve normal airway resistance levels.

There is a moderate correlation between pre expansion volume and $\%$ change in volume (see figure 16). Individuals with a low pre RME nasal cavity volume can be expected to have a relatively large percent increase in volume. This is probably due to the mathematics of proportions. The data cluster found in figure 19 helps explain; as a result of RME many individuals will experience an increase of $1.0-2.0 \mathrm{~cm}^{3}$. Therefore, in a small nasal cavity, this volumetric increase will have a larger impact on percent change. For example, an individual with a pre expansion volume of $5 \mathrm{~cm}^{3}$ and a post expansion volume of $6 \mathrm{~cm}^{3}$ would have a $20 \%$ increase in nasal cavity volume. If the same individual had a pre expansion volume of $10 \mathrm{~cm}^{3}$ and the same $1.0 \mathrm{~cm}^{3}$ increase with a resultant post expansion volume of $11 \mathrm{~cm}^{3}$ and only a $10 \%$ increase in nasal cavity volume.

The Post-Hoc test revealed a significant difference in the amount of reduction in nasal airway resistance between brachyfacial and dolichofacial individuals. This could be the result of many consequences. Inherent anatomical differences; brachyfacial individuals with their wide skeletal maxillofacial region probably have a lower nasal airway resistance prior to RME when compared to the long and narrow dolichofacials. This in effect would minimize the expected reduction in NAR as shown by the scatterplot 
in figure 12. The differences in bone and muscular densities between the face types could also play a role in the amount and ratio of skeletal and dental changes.

This study has conclusively demonstrated that RME will increase the nasal cavity volume and in the majority of cases reduce the NAR. Whether these effects will transform an obligate mouth breather to nasal respiration is highly questionable. ${ }^{40}$ However, it does appear that the effects of RME will set the stage or at least bring an individual closer to nasal respiration. Oral respiration is most likely multifactoral, with turbinates, adenoids, tonsils, and even a habitual component to consider. Another complexity is the fact that most individuals are combination breathers ${ }^{18}$. On one end of the spectrum are the complete nasal breathers and on the opposing end the complete oral breathers. Between the extremes are a multitude of ratios in modes of respiration. The orthodontist can count on RME to help achieve nasal respiration, or at least improve the ratio of nasal to oral breathing. If high levels of oral breathing are suspected after RME as evidenced by subjective and objective measures such as returning cross bite or collapse of the arch, reports from patient/parent, and rhinomanometry the appropriate referral to an ENT physician should follow. 


\section{CONCLUSIONS}

1. All subjects in study did have an increase in nasal cavity volume.

2. $88 \%$ of subjects in study had a reduction in nasal airway resistance.

3. The amount of linear expansion did not correlate with the gain in volume.

4. The amount of nasal cavity volume increase did not correlate with the change in nasal airway resistance.

5. A mean decrease in nasal airway resistance of $36.4 \%$ occurred in subjects. This falls within the range reported in the literature of $36.2-53 \%$.

6. Individuals with a small pre-expansion nasal cavity volume will experience a large percentage wise increase in nasal cavity volume.

7. Individuals with a high pre-expansion nasal airway resistance will experience a large decrease in nasal airway resistance

8. Dolichofacial individuals will experience a greater reduction in nasal airway resistance when compared to the other face types. This difference is the greatest when compared to brachyfacial individuals. 


\section{BIBLIOGRAPHY}

1. Moss ML. The Functional Matrix: Functional Cranial Components. In Krauss BS Reidel (eds): Vistas in Orthodontics. Philadelphia, Lea and Febinger, 1962:85-90.

2. Linder-Aronson S. Adenoids: Their Effect of the Mode Breathing, and Nasal Airflow, and their Relationship to Characteristics of the Facial Skeleton and the Dentition. Acta Otolaryngology 1970:265 supp.

3. Bresolin, D, et al. Mouth Breathing in Allergic Children: Its Relationship to Dentofacial Development. American Journal of Orthodontics. 1983; 83:334-39.

4. Cheng MC. Developmental Effects of Impaired Breathing in the Face of the Growing Child. Angle Orthodontist. Oct 1988; 309-320.

5. Rubin Rm. Mode of Respiration and Facial Growth. American Journal of orthodontics. 1980;78:504-10.

6. Linder-Aronson S. Respiratory Function in Relation to Facial Morphology and the Dentition. British Journal of Orthodontics. 1979; 6:59-71.

7. Linder-Aronson S, et al. Mandibular Growth Direction Following Adenoidectomy. American Journal of Orthodontics. 1986; 89:273-284.

8. Shapiro GC, Shapiro PA. Nasal Airway obstruction and Facial Development. Clinical Review Allergy. 1984; 2:225-35.

9. Schlenker WL, Jennings BD, Jeiroudi MT, Caruso JM. The effects of chronic absence of active nasal respiration on the growth of the skull: a pilot study. Am J Orthod Dentofacial Orthop. 2000;117:706-713.

10. McNamara, JA. Influence of respiratory pattern on craniofacial growth. Angle Orthod. 1981;51:269-300.

11. Harvold, EP. Neuromuscular and morphological adaptations in experimentally induced oral respiration. Naso-Respiratory Function and Craniofacial Growth. 1979;149-164.

12. Miller AJ, Vargervik K. Neuromuscular Changes During Long-term Adaptation of the Rhesus Monkey to Oral Respiration. In: Naso-respiratory function and craniofacial growth. JA McNamara Jr., Craniofacial Growth Series. Center for Human Growth and Development, The University of Michigan, Ann Arbor. 1979;1-26. 
13. Humphreys HF. A Survey of Antero-Posterior Abnormalities of the Jaws in Children Between the Ages of Two and Five and a Half Years of Age. British Dental Journal. Jan 1950; 6: 3-14.

14. Gwynne-Evans, Ballard, CF. Discussion on the Mouth-Breather; Proceedings of the Royal Society of Medicine. 1957; 51:279-85.

15. Leech HL. A Clinical Analysis of Orofacial Morphology and Behavior of 500 Patients Attending an Upper Respiratory Research Clinic. The Dental Practitioner. Dec. 1958; 57-68.

16. Hartgerink DV, et al. The Effect of Rapid Maxillary Expansion on Nasal Airway Resistance. American Journal of Orthodontics and Dentofacial Orthopedics. Nov 1987; 92 (5):381-9.

17. O'Ryan FS, et al. The Relation Between Nasorespiratory Function and Dentofacial Morphology: a Review; American Journal of Orthodontics. Nov 1982; 82 (85): 403-10.

18. Shanker S, et al. A Longitudinal Assessment of Upper Respiratory Function and Dentofacial Morphology in 8- to 12- Year-Old Children. Seminars in Orthodontics. 2004;10(1):45-53.

19. Vig, K. Nasal obstruction and facial growth: The strength of evidence for clinical assumptions. Am J Orthod Dentofacial Orthop. 1998;113:603-611.

20. Subtelny JD. Oral Respiration: Facial Maldevelopment and Corrective Dentofacial Orthopedics. Angle Orthodontist. Jul 1980; 50(3):147-63.

21. Hershey HG, et al. Changes in Nasal Airway Resistance Associated with Rapid Maxillary Expansion. American Journal of Orthodontics: Mar 1976; 69(3) 274-84.

22. Holmber, H. Linder-Aronson S. Cephalometric Radiographs as a Means of Evaluating the Capacity of the Nasal and Nasopharyngeal Airway. American Journal of Orthodontics. 1979;76:479-90.

23. Kohli-Dang, Crysdale. Cephalometric Radiographs and Nasal Resistance. The Journal of Otolaryngology. 1986;15(2): 112-15.

24. Mozzo P, et al. A New Volumetric CT Machine for Dental Imaging Based on the Cone-Beam Technique: Preliminary Results. European Radiology. 1998; 8:15581564.

25. Danforth R, et al. 3-D Volume Imaging for Dentistry: A New Dimension. Journal of the California Dental Association. Nov 2003;31(11): 817-23. 
26. Hirshchberg A, Rhinomanometry: an update. ORL J Otorhinolaryngol Relat Spec. Jul-Aug 2002; 64(4):263-7.

27. Cole P, Fastag O, Forsyth R. Variability in nasal resistance measurements. J Otolarygol. 1980;9:309-315.

28. Kerr A, ed: Rhinology. In: Scott-Brown's Otolaryngology. $6^{\text {th }}$ ed. Oxford: Butterworth-Heinemann; 1997:4/4/5-6.

29. Cummings C: Otolaryngology: Head and Neck surgery. St. Louis, Mo: Mosby Year-Book 1999:801-6, 816, 820.

30. Bailey B, ed: Nasal Function and Evaluation, Nasal Obstruction. In : Head and Neck Surgery Otolaryngology. $2^{\text {nd }}$ ed. New York, NY: Lippincott-Raven: 1998:335$44,376,380-90$.

31. Erbe M. Nasal Airway Changes after Le Fort I-Impaction and Advancement: Anatomical and Functional Findings. Int J. Oral Maxillofac. Surg. 2001: 30: 123129.

32. Shelton DM, Eiser NM. Evaluation of Active Anterior and Posterior Rhinomanometry in Normal Subjects. Clin Otolaryngol. Apr 1992; 17(2):178-82.

33. Berkinshaw, E, et al. The Effect of Methodology on the Determination of Nasal Resistance. Am. J. Orthod. Dentofacial. Orthop. Oct 1987;92(4): 329-335.

34. White BC, et al. The Effect of Rapid Maxillary Expansion on Nasal Airway Resistance. J Otolaryngol. Jun 1989;18(4):137-43.

35. Jones A, Bhatia S. A Study of Nasal Respiratory Resistance and Craniofacial Dimensions in White and West Indian Black Children. Am. J. Orthod. Dentofacial Orthop. 1994 Jul. 106 (1): 34-39.

36. Timms DJ, Trenouth MJ. A Quantified Comparison of Craniofacial Form with Nasal Respiratory Function. Am. J. Orthod. Dentofacial. Orthop. 1998;94:216-21.

37. Timms DJ. The Effect of Rapid Maxillary Expansion on Nasal Airway Resistance. British Journal of Orthodontics. 1986 Oct;13(4):221-8.

38. Proetz A. Physiology of the Nose, Ed. 2, St Louis, Annals Pub; Co: 153: 119-69.

39. Salem SH, et al. Nasorespiratory Function and Craniofacial Morphology-A Review of the Surgical Management of the Upper Airway. Seminars in Orthodontics. 2004;10(1): 54-62. 
40. Warren DW, et al. The Nasal Airway Following Maxillary Expansion. Am J Orthod Dentofacial Orthop. Feb 1987;92(2):11-6. 


\section{UNIVERSITY LIBRARY \\ LOMA LINDA, CALIFORNIA}

APPENDIX

\begin{tabular}{|l|l|l|l|l|l|l|l|}
\hline Patient & Sex & $\begin{array}{l}\text { Face } \\
\text { type }\end{array}$ & $\begin{array}{l}\text { T1 } \\
\text { NAR }\end{array}$ & $\begin{array}{l}\text { T2 } \\
\text { NAR }\end{array}$ & $\begin{array}{l}\text { Exp. } \\
\text { mm }\end{array}$ & $\begin{array}{l}\text { T1Vol } \\
\text { mm }^{3}\end{array}$ & $\begin{array}{l}\text { T2 Vol } \\
\text { mm }^{3}\end{array}$ \\
\hline 1 & F & Brachy. & 1.0 & 0.54 & 9.9 & 8910 & 10790 \\
\hline 2 & F & Dolicho. & 0.58 & 0.26 & 6.1 & 7560 & 9389 \\
\hline 3 & F & Brachy. & 0.68 & 0.29 & 7.0 & 8207 & 10817 \\
\hline 4 & M & Dolicho. & 1.28 & 0.33 & 9.0 & 7213 & 8908 \\
\hline 5 & M & Dolicho. & 0.67 & 0.12 & 9.8 & 5982 & 8657 \\
\hline 6 & F & Dolicho. & 0.28 & 0.20 & 6.7 & 8679 & 10230 \\
\hline 7 & F & Meso. & 0.26 & .08 & 5.3 & 9598 & 10818 \\
\hline 8 & F & Meso. & 0.31 & 0.20 & 5.8 & 10151 & 15869 \\
\hline 9 & F & Dolicho. & 0.63 & 0.48 & 7.0 & 7809 & 9783 \\
\hline 10 & M & Dolicho & 0.41 & 0.24 & 4.4 & 8774 & 12534 \\
\hline 11 & M & Brachy. & 0.30 & 0.31 & 9.0 & 7474 & 9621 \\
\hline 12 & F & Dolicho. & 0.79 & 0.46 & 8.0 & 6284 & 8198 \\
\hline 13 & M & Dolicho. & 0.60 & 0.47 & 4.4 & 9704 & 14526 \\
\hline 14 & M & Dolicho. & 1.20 & 0.61 & 7.6 & 8625 & 10414 \\
\hline 15 & M & Brachy. & 0.53 & 0.50 & 8.2 & 4658 & 11395 \\
\hline 16 & F & Meso. & 1.17 & 0.39 & 6.7 & 6904 & 8389 \\
\hline 17 & F & Meso. & 1.33 & 0.88 & 7.0 & 8831 & 10287 \\
\hline 18 & F & Brachy. & 0.70 & 0.56 & 6.0 & 5396 & 8952 \\
\hline 19 & M & Dolicho. & 2.26 & 0.73 & 5.3 & 8331 & 8888 \\
\hline 20 & M & Dolicho. & 0.69 & 0.29 & 5.3 & 9926 & 10053 \\
\hline 21 & F & Brachy. & 0.59 & 0.82 & 5.0 & 4604 & 5800 \\
\hline 22 & F & Meso. & 0.33 & 0.31 & 5.0 & 7205 & 8701 \\
\hline 23 & M & Meso. & 0.31 & 0.28 & 6.0 & 5739 & 7270 \\
\hline 24 & F & Brachy. & 0.58 & 0.52 & 4.0 & 7512 & 8040 \\
\hline 25 & F & Dolicho. & 0.52 & 0.19 & 4.1 & 5924 & 10693 \\
\hline 26 & F & Dolicho. & 0.34 & 0.38 & 5.0 & 8144 & 13163 \\
\hline 27 & M & Dolicho. & 0.70 & 0.21 & 5.3 & 7353 & 13514 \\
\hline & & & & & & \\
\hline
\end{tabular}

